\title{
Large Synthetic Molecule that either Folds or Aggregates through Weak Supramolecular Interactions Determined by Solvent
}

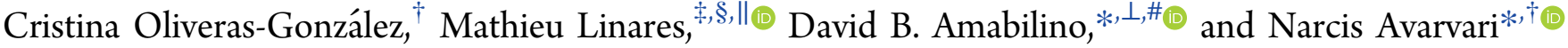 \\ ${ }^{\dagger}$ MOLTECH-Anjou, UMR 6200, CNRS, Univ. Angers, 2bd Lavoisier, 49045 Angers Cedex, France \\ ${ }^{\ddagger}$ Laboratory of Organic Electronics, ITN, Campus Norrköping, ${ }^{\S}$ Scientific Visualization Group, ITN, Campus Norrköping, and \\ "Swedish e-Science Research Centre (SeRC), Linköping University, SE-581 83 Linköping, Sweden \\ ${ }^{\perp}$ School of Chemistry, University of Nottingham, University Park, NG7 2RD Nottingham, U.K. \\ ${ }^{\#}$ GSK Carbon Neutral Laboratories for Sustainable Chemistry, The University of Nottingham, Jubilee Campus, Triumph Road, \\ NG7 2TU Nottingham, U.K.
}

Supporting Information

\begin{abstract}
Weak noncovalent interactions between large disclike molecules in poorly solvating media generally lead to the formation of fibers where the molecules stack atop one another. Here, we show that a particular chiral spacing group between large aromatic moieties, which usually lead to columnar stacks, in this case gives rise to an intramolecularly folded structure in relatively polar solvents, but in very apolar solvents forms finite aggregates. The molecule that displays this behavior has a $C_{3}$ symmetric benzene-1,3,5-tris(3,3'diamido-2,2'-bipyridine) (BTAB) core with three metalloporphyrin units appended to it through short chiral spacers. Quite well-defined chromophore arrangements are evident by

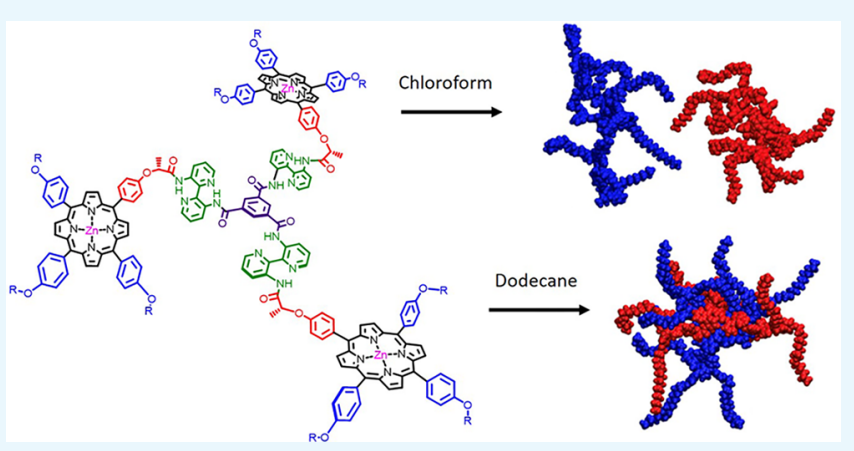
circular dichroism (CD) spectroscopy of this compound in solution, where clear exciton coupled bands of porphyrins are observed. In more polar solvents where the molecules are dispersed, a relatively weak CD signal is observed as a result of intramolecular folding, a feature confirmed by molecular modeling. The intramolecular folding was confirmed by measuring the $\mathrm{CD}$ of a $C_{2}$ symmetric analogue. The $C_{3}$ symmetric $\mathrm{BTAB}$ cores that would normally be expected to stack in a chiral arrangement in apolar solvents show no indication of $\mathrm{CD}$, suggesting that there is no transfer of chirality through it (although the expected planar conformation of the 2,2'-bipyridine unit is confirmed by NMR spectroscopy). The incorporation of the porphyrins on the $3,3^{\prime}$-diamino-2,2'-bipyridine moiety spaced by a chiral unit leaves the latter incapable of assembling through supramolecular $\pi-\pi$ stacking. Rather, modeling indicates that the three metalloporphyrin units interact, thanks to van der Waals interactions, favoring their close interactions over that of the BTAB units. Atomic force microscopy shows that, in contrast to other examples of molecules with the same core, disclike aggregates (rather than fibrillar one dimensional aggregates) are favored by the $C_{3}$ symmetric molecule. The closed structures are formed through nondirectional interlocking of porphyrin rings. The chiral spacer between the rigid core and the porphyrin moieties is undoubtedly important in determining the outcome in polar or less polar solvents, as modeling shows that this joint in the molecule has two favored conformations that render the molecule relatively flat or convex.
\end{abstract}

\section{INTRODUCTION}

The literature is replete with examples of large organic molecules of disclike or calamitic shapes that assemble to give fibrillar nanostructures. ${ }^{1-3}$ These organic $\pi$-conjugated molecules with columnar organization driven by the cofacial stacking of aromatic moieties surrounded by alkyl chains offer great possibilities for the creation of nanomaterials applicable in energy or charge transport in organic electronic devices, such as solar cells or organic field-effect transistors. ${ }^{4,5}$ While different rotational symmetries have been studied for discotic molecules, ${ }^{6}$ the $C_{3}$ symmetrical structures have become among the most popular ones. ${ }^{7,8}$ These molecules generally contain a central core linked to three identical arms often endowed with electronic and optical properties that can be modulated by the supramolecular organization and morphology at the nano- and meso-scale. ${ }^{9}$ Of special interest from a point of view of the self-assembly processes and supramolecular chirality are the 1,3,5-benzenetricarboxamides (BTA) and related compounds. ${ }^{10-13}$ The ability to modify systematically the peripheral arms emanating from the BTA core offers a great number of functional derivatives such as water soluble supramolecular polymers, ${ }^{14}$ zwitterionic hydro-

Received: April 12, 2019

Accepted: May 29, 2019

Published: June 11, 2019 

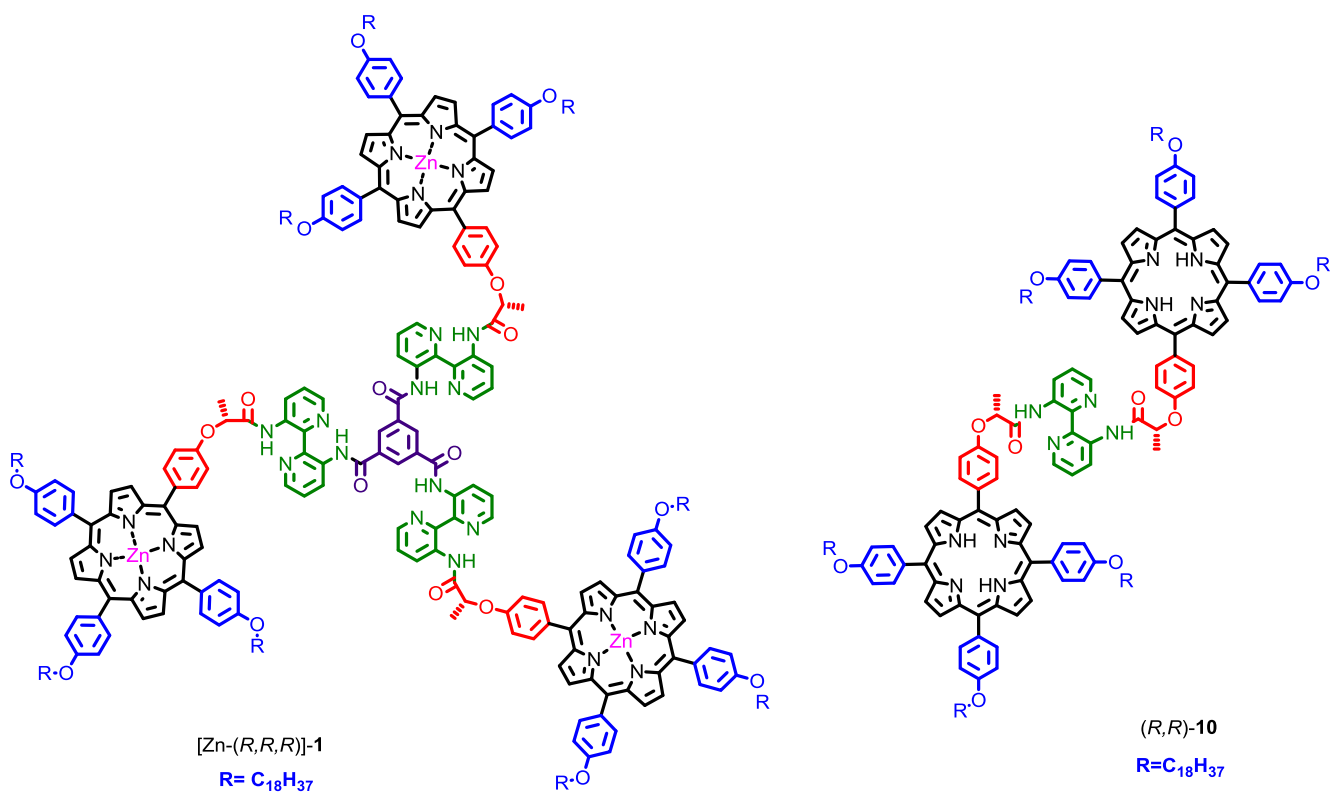

Figure 1. Structure of $C_{3}$ symmetric tris-porphyrin $[\mathrm{Zn}-(R, R, R)]-\mathbf{1}$ and bis-porphyrin $(R, R)-\mathbf{1 0}$.

gels for the encapsulation of hydrophobic guests in water, ${ }^{15}$ or naphthalene diimide-based helical fibers. ${ }^{16}$ The peripheral substituents can be either directly covalently linked to the central aromatic amide platform, ${ }^{17-20}$ or can be connected through a spacer such as $3,3^{\prime}$-diamino-2,2'-bipyridine that can control the self-assembly process of the molecule. ${ }^{21}$ The intramolecular hydrogen bonding within this unit provides a rigid disc-shaped moiety favoring self-assembly driven by $\pi-\pi$ stacking. ${ }^{22,23}$

A broad variety of such $C_{3}$ derivatives exists based on the 1,3,5-benzenecarboxamide core bonded to 3,3' -diamino-2,2' bipyridine, first described by Meijer and coworkers. ${ }^{24,25}$ For example, tetrathiafulvalene (TTF) compounds providing electroactive xerogels, ${ }^{26}$ and donor-acceptor organogels based on luminescent pyrene groups ${ }^{27}$ have shown fascinating behavior. Introduction of chiral peripheral substituents can ultimately lead to helical columnar supramolecular architectures upon a hierarchical self-assembly process. $^{28-31}$ In the case of chiral TTF derivatives, helical electroactive aggregates showing inversion of supramolecular chirality between solution and solid states were obtained. ${ }^{32-34}$ All of these examples display a fibrillar morphology thanks to the driving force provided by stacking of the core of the molecules. However, here we will show that intramolecularly folded structures and discrete oligomers are also possible for this type of $C_{3}$ compound. Other molecular topologies have shown folding behavior, for example, a topologically linear compound incorporating a $\pi$-electron donor as well as a $\pi$-electron acceptor was shown to form a folded structure or a reverse vesicle depending on the solvent, ${ }^{35}$ while a bis(pyrene-urea) organogelator adopted a solvent and temperature-dependent folded structure evidenced by pyrene...pyrene excimer-based emission. ${ }^{36}$ The situation is reminiscent of proteins where the folded and extended conformations can be responsible for different functions, ${ }^{37}$ such as in adenosine 5 -triphosphate (ATP) synthase for which it has been proposed that the compact state of the protein subunit e from Escherichia coli allows both ATP synthesis and hydrolysis to occur, while the extended conformation only permits the ATP synthesis. ${ }^{38,39}$ Another interesting example in biochemistry highlighting the importance of controlling the folded/extended conformation of an active unit is represented by the nicotine amide dinucleotide coenzyme which shows extended structures when linked to a protein, ${ }^{40}$ while in the free state it adopts a folded conformation. ${ }^{41}$

Our interest in the tris(diamido-bipy)-BTA core was kindled by the possibility of appending porphyrins to it. These functional units, along with the broader family of tetrapyrrolic macrocycles linked by methine bridges, are naturally occurring chromophores ${ }^{42}$ that are essential for the photosynthetic pathway ${ }^{43}$ and in electron transport and light harvesting processes. ${ }^{44}$ Self-assembled chiral systems based on synthetic porphyrins ${ }^{45}$ present a broad range of potential applications in areas such as photovoltaic cells, ${ }^{46,47}$ sensors, ${ }^{48}$ optoelectronic $^{49,50}$ and nanoelectronic devices, ${ }^{49}$ and also nonlinear optical materials. ${ }^{51,52}$ The use of porphyrin rings as a peripheral arm in $C_{3}$ symmetric molecules can in principle allow formation of helical stacks with optical and electronic properties as reported by Elemans et al. ${ }^{53}$ More recently, Vela et al. have investigated chiral and achiral tris(porphyrin) discotic $C_{3}$ derivatives based on the benzenetricarboxamidebipyridine platform that stacks to give superhelical fibers. ${ }^{54} \mathrm{On}$ the other hand, it has been shown that introduction of chiral centers in the porphyrin moiety as well as metal ions can influence hierarchical transfer of chirality into a material morphology. ${ }^{55}$

We report herein the synthesis, characterization, and selfassembly of the $C_{3}$ symmetric tris[3-(3'-carbamoylamino)2,2'-bipyridyl]-benzene-1,3,5-tricarbonamide derivative 1 containing three chiral metalloporphyrin units at the periphery as well as the related $C_{2}$ symmetric bipyridyl-bis-porphyrin 10 (Figure 1).

The hierarchical self-assembly in solution was investigated by circular dichroism (CD) measurements, well adapted for chiral porphyrins, ${ }^{56}$ while the morphology of the aggregates was investigated by atomic force microscopy (AFM) after casting dilute solutions onto surfaces. ${ }^{47}$ For this purpose, different solvents were used to investigate the influence of the polarity of the solvent on the supramolecular organization of the $C_{3}$ molecules, as well as the influence of the nature of the 
Scheme 1. Synthetic Route for $C_{3}$ Compound $[\mathrm{Zn}-(R, R, R)]-1$ and $C_{2}$ Compound $(R, R)-10$
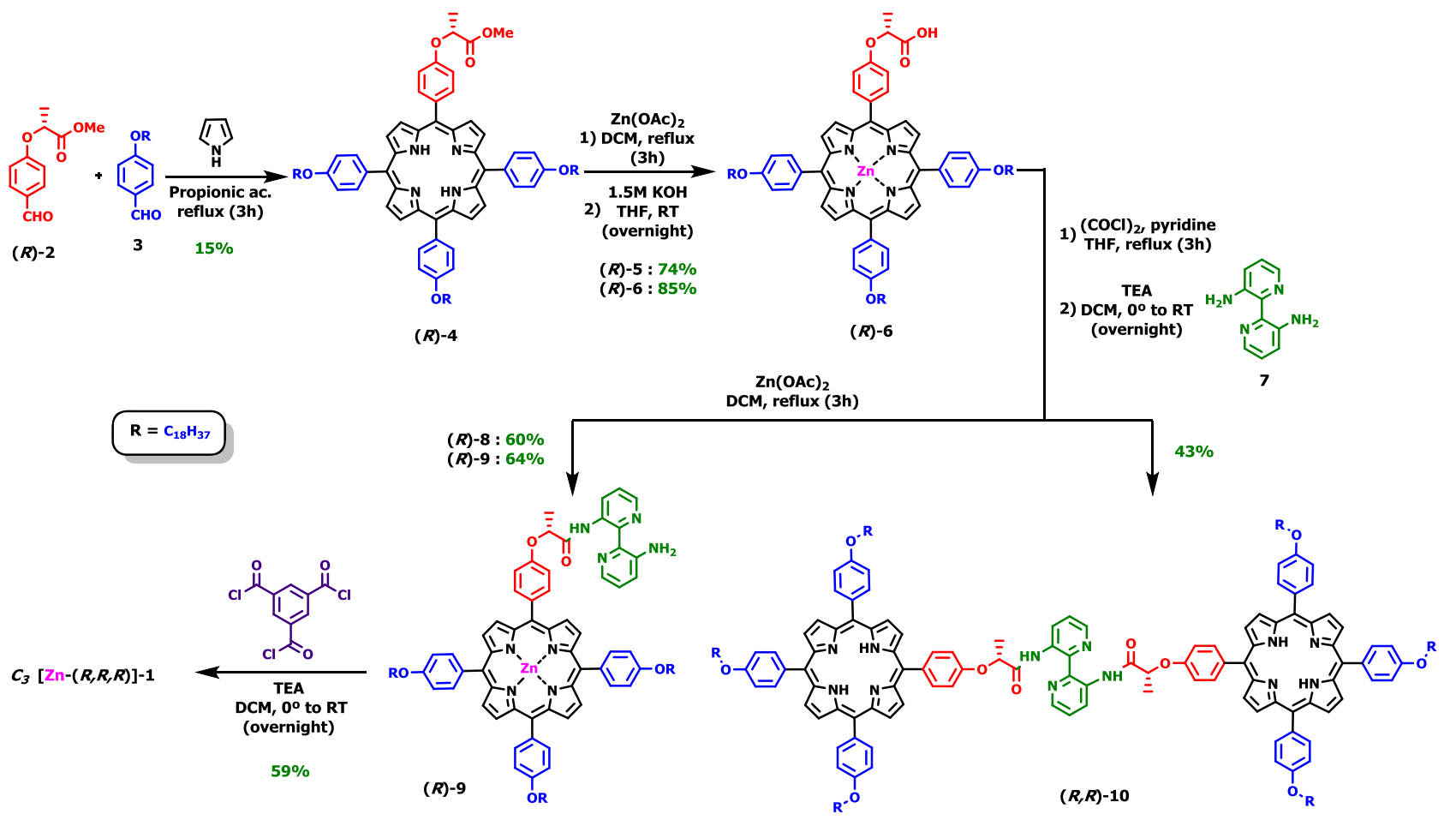

surface in the organization over it. In addition, to estimate the role of the central platform on the self-assembly process $C_{2}$ symmetric derivative $\mathbf{1 0}$ was investigated. The results, supported and enlightened by molecular modeling, show finite aggregate growth in apolar solvents as a result of the particular conformation of the linker between the rigid core and essentially flat porphyrins.

\section{RESULTS AND DISCUSSION}

Synthesis. $C_{3}$ and $C_{2}$ symmetric compounds $[\mathrm{Zn}-(R, R, R)]$ 1 and $(R, R)-10$ were prepared using the synthetic route shown in Scheme 1.

The free-base chiral porphyrin intermediate $(R)-4$ was prepared in one step by condensation of $(R)$-methyl 2-(4formylphenoxy)propanoate $(R)-2^{57}$ and 4-octadecaneoxybenzaldehyde $3^{58}$ with pyrrole in refluxing propionic acid in air. Then, the insertion of zinc(II) into the porphyrin core was performed by the reaction of the acetate metal salt with the free-base porphyrin derivative in a refluxing mixture of (dichloromethane) $\mathrm{DCM} / \mathrm{MeOH}$ to give the metallocompound $(R)-5$ (not shown in Scheme 1), which subsequently was reacted with $\mathrm{KOH}$ to obtain the lactic acid-derived porphyrin $(R)-6$ after dissolution in a chlorinated solvent and washing with acidic aqueous solution. The condensation of the corresponding acid chloride, obtained by reaction of $(R)-6$ and oxalyl chloride, with the $3,3^{\prime}$-diamino-2,2' $2^{\prime}$-bipyridine $7^{59}$ provided the monoacylated porphyrin-bipy derivative $(R)-8$ (not shown in Scheme 1) with only traces of the bis-porphyrin compound. Note that during the coupling process the zinc(II) metal ion is ejected from the porphyrin ring as a result of the acidic conditions employed for the formation of the acid chloride derivative. ${ }^{60}$ Monoacylated zinc porphyrin ( $R$ )-9 was then obtained as described above. The subsequent reaction of (R)-9 with trimesic acid chloride afforded the final $C_{3}$ compound $[\mathrm{Zn}-(R, R, R)]-1$. Alternatively, when two equiv- alents of acid chloride of (R)-6 were reacted with 7, bisporphyrin compound $(R, R)-\mathbf{1 0}$ was obtained (Figure $S 1)$.

Self-Assembly Studies by CD. CD spectroscopy is an important tool for studying the self-assembly of chiral chromophores because of its sensitivity to the supramolecular structure and absolute configuration. ${ }^{61}$ The chiral $C_{3^{-}}$symmetric discotic molecule $[\mathrm{Zn}-(R, R, R)]-1$ herein designed can, in principle, self-assemble through multiple noncovalent interactions that involve the various groups in the compound. First, the bipyridine moieties rigidify the structure thanks to intramolecular hydrogen bonding, adopting a propeller-like conformation around the central core and in principle engaging in intermolecular $\pi-\pi$ interactions to provide helical twists. In addition, here, the $\pi-\pi$ interactions directly related with the porphyrin skeleton as well as the coordination of the carbonyl groups to the zinc metal ions can promote supramolecular organization, while van der Waals interactions between the peripheral alkyl chains may also play a role in the resulting architecture. Generally, the noncovalent interactions involved in the hierarchical self-assembly and their strength also depends on the nature of the solvent used. ${ }^{62}$

The self-assembly studies of $C_{3^{-}}[\mathrm{Zn}-(R, R, R)]-\mathbf{1}$ were performed in different solvents in order to observe the influence of the polarity on the formation of the aggregates through their chiroptical activity. For these studies, chloroform, 1,4-dioxane, methylcyclohexane $(\mathrm{MCH})$, and dodecane have been chosen, with the degree of polarity ranging from chloroform, as the most polar one, to dodecane, as the most apolar. $^{63}$

Solutions of $C_{3}-[\mathrm{Zn}-(R, R, R)]-1$ in each solvent were prepared (at a concentration $5 \mu \mathrm{M}$ ), and CD spectra were recorded in a range of temperatures (different for each solvent) after one heating and cooling cycle to probe the assembly under equilibrium conditions. All of the experiments were performed by recording spectra in both heating and cooling ramps. It was observed that the $\mathrm{CD}$ spectra from the different 

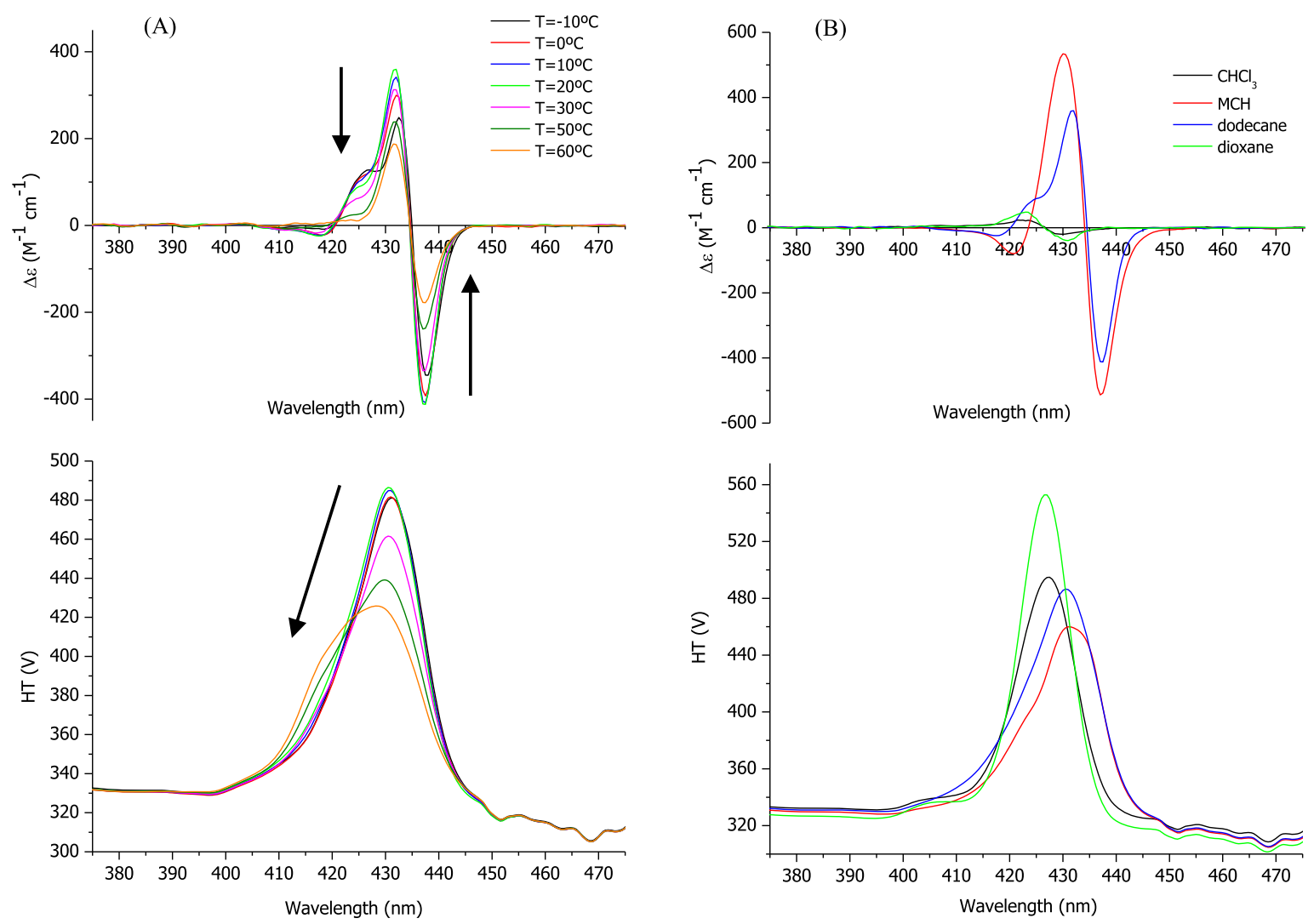

Figure 2. Variable temperature $\mathrm{CD}$ spectra for compound $C_{3^{-}}[\mathrm{Zn}-(R, R, R)]-1(5 \mu \mathrm{M})$ in dodecane $(\mathrm{A})$ and comparison of $\mathrm{CD}$ spectra for the compound $C_{3}$ - $[\mathrm{Zn}-(R, R, R)]-1(5 \mu \mathrm{M})$ at room temperature in different solvents $(\mathrm{B})$.

solvents do not experience clear differences in the temperatures studied, showing a bisignate CD signal at the position of the Soret band of the porphyrin, slightly different for each solvent, even at higher temperatures (up to $60{ }^{\circ} \mathrm{C}$ ). It should be noted that the molecular CD (i.e., that of the totally dissolved molecule free from aggregation) is expected to give a very weak signal because the stereogenic center is far from the chromophore in the system. ${ }^{55}$ These results suggest either that the aggregates form in different solvents for the $C_{3}$ compound independently of the temperature, or that intramolecular dipolar couplings take place in the solvent isolated $C_{3}$ molecule, ${ }^{64}$ especially in the more polar solvents (Figure 2 ).

The intensity observed in the $\mathrm{CD}$ bands clearly show, however, a dependence with the nature of the solvent, being much less intense for the more polar solvents (Figure 2B).

Figure $2 \mathrm{~B}$ shows the low optical activity observed for $\mathrm{CHCl}_{3}$ and dioxane with a bisignate signal with maxima at $430 \mathrm{~nm}$ (negative) and $421 \mathrm{~nm}$ (positive). On the contrary, when the spectra are measured in $\mathrm{MCH}$ and dodecane the optical activity observed is an order of magnitude higher than in the more polar solvents. In the case of $\mathrm{MCH}$ a strong negative trisignate signal with maxima at 437,430 , and $420 \mathrm{~nm}$ was noticed, while similar results were observed in the case of the dodecane, but with a positive shoulder located at $426 \mathrm{~nm}$, suggesting that slightly different types of porphyrin-porphyrin interactions take place.

As the $C_{3}$ compound is soluble in chloroform, the polar character of this solvent does not favor, in principle, the selfassembly. Nevertheless, optical activity, albeit relatively weak, is observed for $\mathrm{CHCl}_{3}$ solutions of $[\mathrm{Zn}-(R, R, R)]-\mathbf{1}$, suggesting a probable intramolecular dipole coupling between the chromophores (vide infra), a hypothesis supported by the absence of any CD signal for the mono(porphyrin)-bipy precursor $(R)-8$ in solution at a similar concentration (Figure S2). In the case of dioxane, a solvent that in principle might be thought to favor aggregation, the low intensity $C D$ signal of $[\mathrm{Zn}-(R, R, R)]-\mathbf{1}$ indicates that either small aggregates were formed, or, once again, that intramolecular exciton coupling can take place to some degree (Figure S3).

The optical activity observed in the CD spectra from solutions of $[\mathrm{Zn}-(R, R, R)]-\mathbf{1}$ in $\mathrm{MCH}$ and dodecane was much stronger than for the two more polar solvents indicating that the apolar solvents favor the self-assembly of this $C_{3}$-symmetric molecule.

It is worth noting that the Cotton effect observed for $\mathrm{MCH}$ and dodecane (see also Figure S4) solutions is much more intense and slightly red-shifted compared to the solutions of chloroform and 1,4-dioxane, probably because of the formation of aggregates through the interactions between the porphyrins as a result of J-type aggregation.

Commonly, as mentioned above, the families of $C_{3}$ symmetric molecules based on the benzene-1,3,5-tris(amido$2,2^{\prime}$-bipy) cores self-assemble through $\pi-\pi$ stacking of the bipyridine units that rigidify around the central core by intramolecular hydrogen bonding (as seen clearly in the NMR spectra of these compounds). However, the lack of any CD signal coming from the $\pi-\pi^{*}$ transition of these units, which should appear in the region from 360 to $390 \mathrm{~nm},{ }^{25}$ suggests that the self-assembly is not driven by the $C_{3}$ central core, unlike all the other aggregates that we are aware of derived from this building block. For $[\mathrm{Zn}-(R, R, R)]-\mathbf{1}$, the driving force for aggregation is apparently through close interactions of the 
porphyrin rings, as suggested by the intense CD active Soret band.

Interestingly, the $C_{2}$-symmetric compound $(R, R)-\mathbf{1 0}$ also shows temperature-independent $C D$ activity in dioxane solutions in the Soret band region, with a negative couplet characterized by maxima at 425 and $417 \mathrm{~nm}$ (Figure 3).

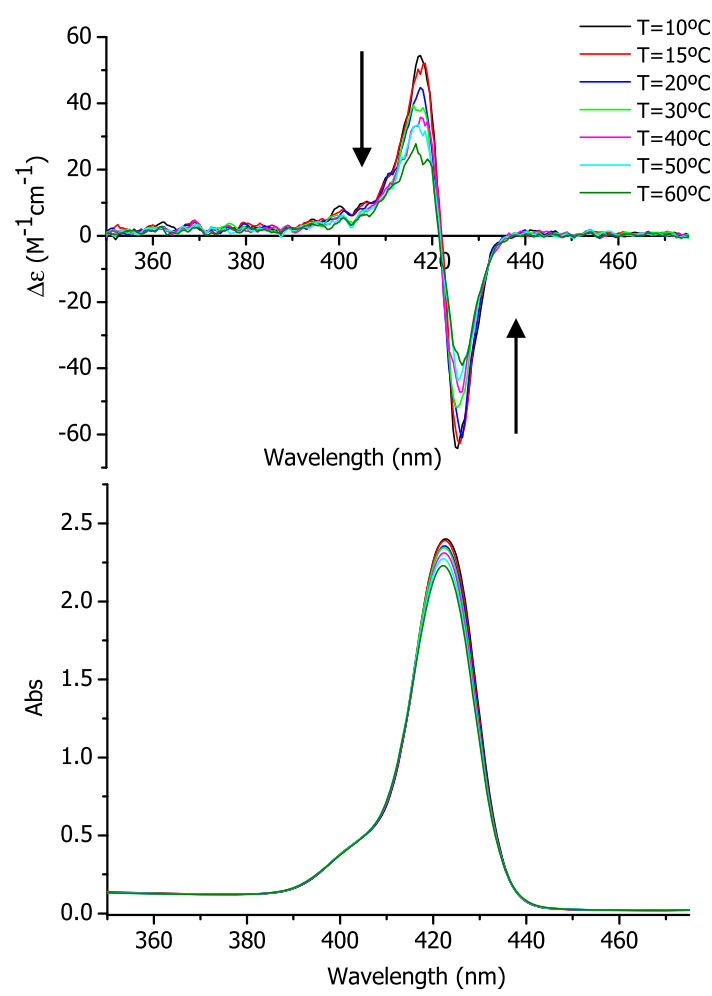

Figure 3. Variable temperature $\mathrm{CD}$ spectra for compound $(R, R)-10$ $(5 \mu \mathrm{M})$ in dioxane.

We hypothesize here again that the observed CD activity is a result of the intramolecular exciton coupling, as indicated by the relatively low optical activity of the signal. It is well-known for bis-porphyrin systems that the intensity of the exciton coupling signal is strongly dependent on the interchromophoric distance and their mutual orientation. ${ }^{65}$ The magnitude of the CD signal is similar to that of $[\mathrm{Zn}-(R, R, R)]-1$ in the same solvent. The slight temperature dependence of these bands in polar solvents could be a result of the changes in the molecular conformation, with the arrangement at low temperatures favoring the intramolecular interaction. Indeed, the temperature dependence of the absorption bands of [ $\mathrm{Zn}$ $(R, R, R)]-\mathbf{1}$ in polar solvents is very different to that in dodecane (Figure S5), as also seen in the bis(porphyrin) compound $(R, R)-10$ (Figure S6). The intramolecularly folded conformation shows a slight temperature dependence, while the dodecane sample shows a more abrupt loss of the $\mathrm{CD}$ signal above $20{ }^{\circ} \mathrm{C}$, indicating disassembly of the aggregate, consistent with the broadening and concomitant blue shift of the corresponding absorption band.

Molecular Modeling. Considering the large size of bis(porphyrin) $(R, R)-\mathbf{1 0}$ and $[\mathrm{Zn}-(R, R, R)]-\mathbf{1}$, calculations have been performed on model systems of growing size with a combination of molecular mechanics (MM) and dynamics (MD) as well as density functional theory (DFT) calculations (see Computational Details).

Bis-porphyrin $(R, R)-10$. For the bis-porphyrin $(R, R)-10$, a simplified model without any stereogenic center and with simple porphyrin without any phenyl moieties attached to it were employed. MM reveals that the two most stable conformers present a large interaction between the porphyrin cores that stabilize the system through $\pi-\pi$ interactions. Those two conformers are mirror images of one another, with $\mathrm{P}$ and $\mathrm{M}$ helical configurations (see Figure S7). Other conformers were identified presenting weak or no interaction between the porphyrin cores, but those conformers are much higher in energy. When adding the methyl group to form the $\mathrm{R}$ stereogenic center, the $\mathrm{M}$ conformer has methyl in the axial position and the $\mathrm{P}$ conformer will have methyl in the equatorial position (Figure 4A,B). This situation favors the $\mathrm{M}$ conformer by $7.3 \mathrm{kcal} / \mathrm{mol}$ in comparison with $\mathrm{P}$ at the DFT level of theory. For the more stable conformer $\mathrm{M}$ we computed the absorption and electron-capture detector (ECD) spectra (Figure 4C,D). We obtained a very clear bisignate signal for
A

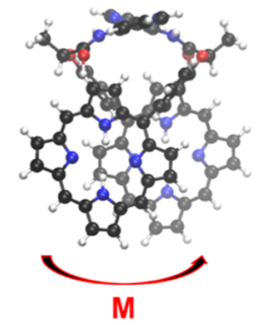

B

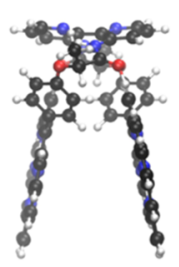

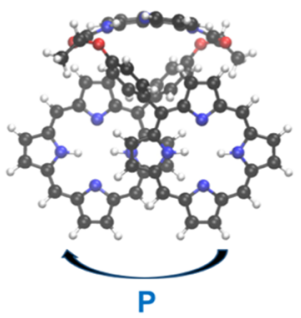

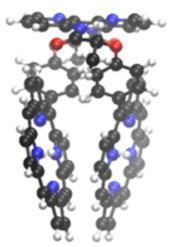

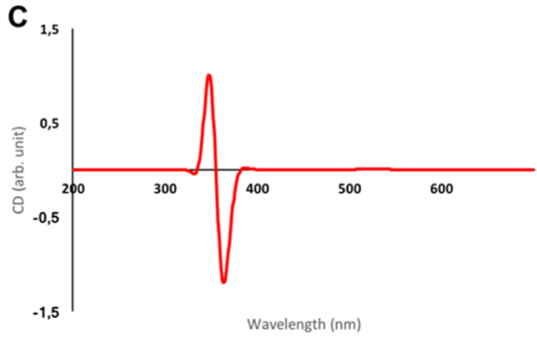

D

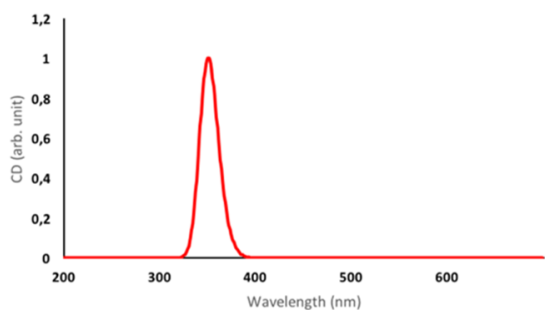

Figure 4. $\mathrm{P}$ and $\mathrm{M}$ conformers $(\mathrm{A}, \mathrm{B})$ and calculated $\mathrm{ECD}$ and absorption spectra of the $\mathrm{M}$ conformer $(\mathrm{C}, \mathrm{D})$ of the bis-porphyrin $(R, R)-10$. 
A

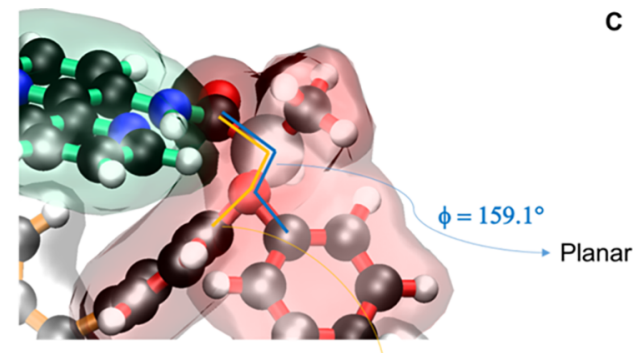

в

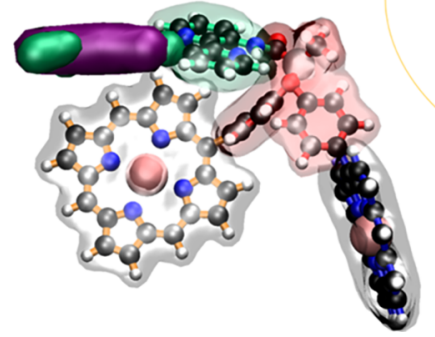

C

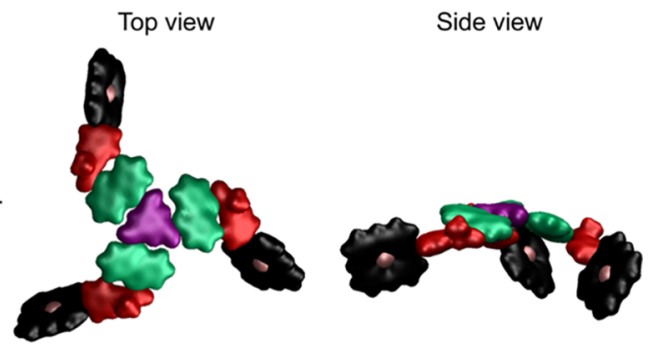

Folded
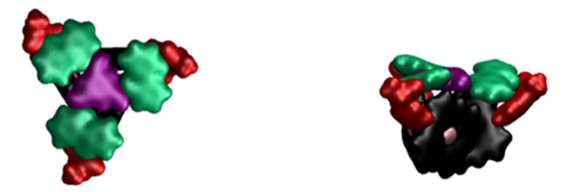

Figure 5. (A) Definition of the dihedral angle $\phi$ and (B) representation of the two possible conformations for the porphyrins (only one porphyrin was shown for clarity). (C) Top and side view for the folded and planar conformation.

the Soret band around $350 \mathrm{~nm}$ with a clear -/+ sign typical of an $\mathrm{M}$ helix, in good agreement with the experiment. The discrepancy between the experiment and theory for the position of the peak can be explained by the simplification of the model and the lack of the solvent in the calculation. Finally, for the $\mathrm{M}$ conformer, we introduced the phenyl rings and short tails made of five carbon atoms, the system being now composed of 290 carbon atoms. It is noticeable that the introduction of the phenyl groups and tails has an influence on the overlap between the porphyrin cores, reinforcing it (see Figure S8).

Tris-porphyrin $[Z n-(R, R, R)]-1$. As for the bis-porphyrin $(R, R)-10$, the conformational study reveals that the methyl group of the stereogenic center in $[\mathrm{Zn}-(R, R, R)]-\mathbf{1}$ will prefer to sit on the axial position, with the phenyl moieties that link it to the porphyrin situated below the core of the molecule (Figure 5). Moreover, two possible values have been identified for the dihedral angle $\phi$ responsible for the position of the phenyl and porphyrins moieties and two conformers can be identified, namely, a folded and a more planar conformation. In the folded conformation $\left(\phi=54.3^{\circ}\right)$, the three porphyrins are folded below the core of the molecule (BTA + bipyridine), while in the planar conformation $\left(\phi=159.1^{\circ}\right)$ the porphyrins are approximately in the same plane of the core of the molecule.

To assess how those two conformations of $[\mathrm{Zn}-(R, R, R)]-1$ will behave in different solvents, we performed $M D$ simulations in dodecane and chloroform with both the folded and open conformations as starting points. It appears that independently of the solvent, the molecule undergoes rapid conformational changes with the porphyrin arms changing several times between folded and flat conformations during the $50 \mathrm{~ns}$ of the dynamics run.

Then, we performed a simulation with a dimer of $C_{3}$ - $[\mathrm{Zn}$ $(R, R, R)]-1$ with flat conformers placed in dodecane and chloroform (see Computational Details). At the beginning of the simulations the molecules are close to each other as can be seen in Figure 6, but the behavior of the dimer differs drastically in the two solvents. In chloroform they separate gradually and flip between the flat and folded conformation to

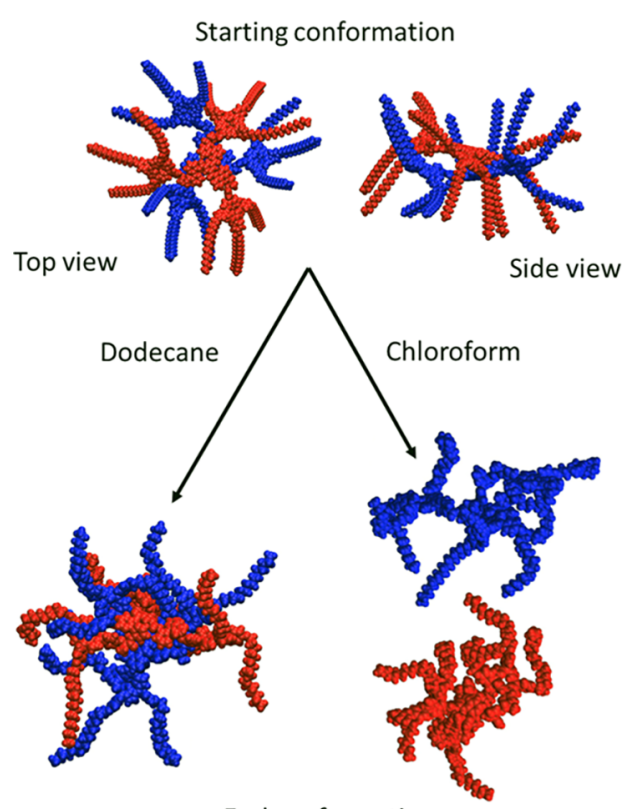

End conformations

Figure 6. Behavior of a dimer of $C_{3}-[\mathrm{Zn}-(R, R, R)]-1$ in different solvents. In chloroform the two molecules separate along the $\mathrm{MD}$ trajectory, while in dodecane the two molecules stay together for the whole dynamic.

reach a distance of $5 \mathrm{~nm}$ at the end of the dynamic (50 ns), while in dodecane, the two molecules stayed together for the whole dynamic. This can be observed looking at the van der Waals and Coulombic interactions between the two molecules and between each molecule and the solvent (Figures S9 and S10). Indeed, in dodecane we see that the main contribution between the two molecules is due to the van der Waals interaction which increased along the trajectory together with a decrease of the interaction between the molecule and the solvent. For chloroform however, the van der Waals interaction decreases as the molecules separate. This behavior in different solvents seems to indicate that $C_{3^{-}}[\mathrm{Zn}-(R, R, R)]-1$ will have a tendency to aggregate in apolar solvents such as dodecane or $\mathrm{MCH}$, and to remain isolated in polar solvents such as 


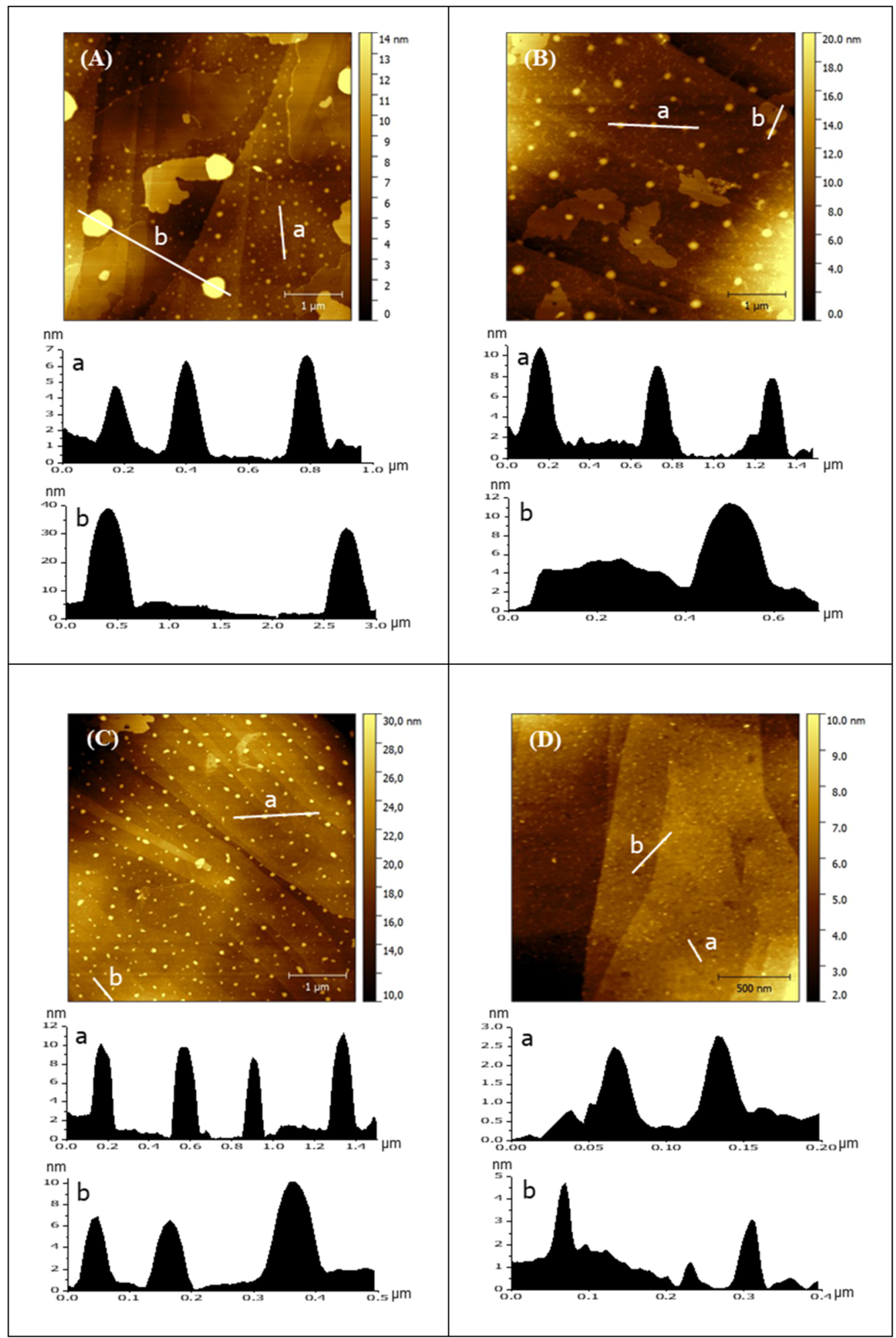

Figure 7. Tapping mode AFM images of one drop of $C_{3}$ - $[\mathrm{Zn}-(R, R, R)]-1(5 \mu \mathrm{M})$ on freshly cleaved HOPG. Chloroform (A), 1,4-dioxane (B), $\mathrm{MCH}(\mathrm{C})$, dodecane (D).

chloroform and dioxane. This allows us to attribute the weak ECD signal in the polar solvent to an intramolecular chirality while the large ECD signal in the apolar solvent is attributed to the intermolecular chirality resulting from exciton coupling between the porphyrins in neighboring molecules in the aggregate.
Morphology Studies by AFM. In order to determine the morphology of the apparent aggregates observed by $\mathrm{CD}$ spectroscopy, we studied the material left upon evaporation of solutions of $[\mathrm{Zn}-(R, R, R)]-1$ on flat surfaces. The discotic molecule $[\mathrm{Zn}-(R, R, R)]-1$ was studied in different solvent solutions (all at an initial concentration of $5 \mu \mathrm{M}$ ) that were deposited on solid supports by drop casting, allowing the 
aggregates to be investigated by AFM using the intermittent contact mode.

A number of parameters play important roles in the process of transferring the self-assembly molecules from the solution to a solid support such as molecule-molecule or moleculesurface interactions, as well as the solvent-surface interaction and evaporation rates. ${ }^{66}$ The nature of the surface is an important factor to take into account to successfully adsorb the aggregates in a controlled way because of the significant molecule-surface interactions or because of dewetting of the solution from the surface. ${ }^{67}$

In this work, different surfaces were used to study the hierarchical organization of the $C_{3}$ molecules when one drop of solutions was deposited on the surface. Highly oriented pyrolitic graphite (HOPG) was chosen for its hydrophobic character, which favors the van der Waals interactions between the surface and the long alkyl chains at the periphery of the porphyrin ring. ${ }^{68}$ On the other hand, a hydrophilic surface such as mica that could interact with the core of $C_{3}$ through the amide groups was also tested. ${ }^{69,70}$

Topographic images on HOPG show globular objects as the main morphology when solutions of the discotic molecule were cast on the surface (Figure 7). The profile of the larger objects reveals heights of about $30 \mathrm{~nm}$ in the case of chloroform, while the small objects observed present heights around $7 \mathrm{~nm}$. In the case of the dodecane sample it was difficult to scan the sample very accurately, even working in the tapping mode, as the tip was sticking to the surface. However, as Figure 7D shows, the surface is covered by very small globular objects with heights around $3 \mathrm{~nm}$ that might correspond to dimer aggregates. The difference in height of the aggregates between solvents might suggest that the evaporation rate is an important factor to take into account for the formation of the globular aggregates. Notably, the samples from both chloroform and dioxane show large flat domains in addition to the globular objects (Figure $7 \mathrm{~A}, \mathrm{~B})$. These areas are interpreted as monolayer regions resulting from the deposition of monomers during the concentrating solution, leading to the formation of these flat areas. Also, importantly, all of the samples show smaller disclike aggregates, seen most clearly for the dodecane solution that might indicate the formation of dimers of the compound that could explain the spectroscopic observations in solution.

One drop of solutions of the $C_{3}-[\mathrm{Zn}-(R, R, R)]-1$ compound in the previously mentioned solvents was also deposited onto a mica surface (see Figure S11). Their topographic images analyzed by AFM show that the major objects observed on the surface present the globular morphology of large objects with an average height of $60 \mathrm{~nm}$, indicating a nonspecific aggregation possibility as a result of dewetting from the hydrophilic surface upon evaporation of the solvent.

\section{CONCLUSIONS}

The CD study of $[\mathrm{Zn}-(R, R, R)]-\mathbf{1}$ indicates a conformation with intramolecular porphyrin interactions in polar solvents, where the optical activity is weaker than in the case of supramolecular aggregates. The conformers are sensitive to temperature, and molecular modeling indicates that folding of the molecule appears to be challenged because of the largely rigid structure. Theoretical calculations do predict a weak interaction between the porphyrin rings that could explain the observed CD signals for the molecularly dissolved compounds. The incorporation of the porphyrins on the $3,3^{\prime}$-diamido-2,2'bipyridine unit through the chiral linker apparently renders the aromatic units incapable of entering into significant supramolecular $\pi-\pi$ stacking. Rather, in apolar solvents, the porphyrin moieties overlap giving rise to greater optical activity. The AFM measurements clearly show that this aggregation is not a result of a fibrillar one dimensional assembly, unlike other examples of molecules with the same core. In the present case the objects presumably form closed structures because of the relatively nondirectional interlocking of porphyrin rings. The chiral spacer between the rigid core and the porphyrin moieties could be important in determining this mode of self-assembly in these and other supramolecular materials. $^{71}$

\section{EXPERIMENTAL SECTION}

Materials and Methods. ( $R$ )-Methyl 02-(4formylphenoxy)propanoate $(2)^{57}$ and $3,3^{\prime}$-diamino-2,2' -bipyridine $(7)^{59}$ were prepared according to the literature procedures. All other starting materials were purchased from commercial sources and used as received. The NMR spectra were recorded in a $\mathrm{CDCl}_{3}$ solution, and ${ }^{1} \mathrm{H}$ NMR spectra were measured either on a Bruker AVANCEII 300 or Bruker AVANCE DRX 300. ${ }^{1} \mathrm{H}$ NMR spectra are referenced to the residual protonated solvent $\mathrm{CHCl}_{3}\left({ }^{1} \mathrm{H}, \delta=7.26, \mathrm{CDCl}_{3}\right)$. Mass spectrometry was performed with an Ultraflex (TOF/ TOF) spectrometer (LDI-TOF) and on a Bruker Biflex-IIITM apparatus, equipped with a $337 \mathrm{~nm} \mathrm{~N}$ laser (MALDI-TOF). All Fourier transform infrared measurements were recorded with a PerkinElmer (spectrum one) apparatus. The samples were solid compounds (recovered after evaporation of the solvent in a noncontrolled precipitated way) and measurements were performed in the attenuated total reflection (ATR) mode. The samples were measured on the plate of universal ATR. Topographic AFM images were acquired in the dynamic tapping mode using a FORT Si tip in the Servei de AFM of the ICMAB (Barcelona, Spain) in an Agilent 5100 microscope. Solutions of $C_{3}-[\mathrm{Zn}-(R, R, R)]-1$ were drop casted onto a HOPG surface or mica surface, and measurements were performed under ambient conditions. The color code in all the images shown is such that dark are lower and bright are higher values of the height.

Synthesis. 4-Octadecaneoxy-benzaldehyde (3). 4-Hydroxy-benzaldehyde $(4.00 \mathrm{~g}, 32.75 \mathrm{mmol})$ and $\mathrm{K}_{2} \mathrm{CO}_{3}(13.60$ $\mathrm{g}, 98.25 \mathrm{mmol})$ were dissolved in acetonitrile $(82 \mathrm{~mL})$ and the solution was stirred at room temperature for $1 \mathrm{~h}$. Then, 1bromoctadecane (10.92 g, $32.75 \mathrm{mmol}$ ) was added to the aldehyde solution and the mixture was stirred under reflux during $48 \mathrm{~h}$. The crude was then filtrated under warm conditions and the resulting solution was cooled down at room temperature when a precipitate appeared. The desired white solid was filtrated in a porcelain filter funnel $(4.48 \mathrm{~g}, 83 \%) .{ }^{1} \mathrm{H}$ NMR (250 MHz, $\mathrm{CDCl}_{3}$, r.t., ppm): $\delta 9.88$ (s, $1 \mathrm{H} ; \mathrm{CHO}$ ), 7.83 (d, $J=8.8 \mathrm{~Hz}, 2 \mathrm{H}$; ArH), 6.99 (d, $J=8.7 \mathrm{~Hz}, 2 \mathrm{H} ; \operatorname{ArH}$ ), $4.04\left(\mathrm{t}, J=6.5 \mathrm{~Hz}, 2 \mathrm{H} ; \mathrm{OCH}_{2} \mathrm{CH}_{2}\left(\mathrm{CH}_{2}\right)_{15} \mathrm{CH}_{3}\right), 1.81(\mathrm{dt}, J=$ $\left.14.5,6.6 \mathrm{~Hz}, 2 \mathrm{H} ; \mathrm{OCH}_{2} \underline{\mathrm{CH}}_{2}\left(\mathrm{CH}_{2}\right)_{15} \mathrm{CH}_{3}\right), 1.25(\mathrm{~m}, 30 \mathrm{H}$; $\left.\mathrm{OCH}_{2} \mathrm{CH}_{2}\left(\underline{\mathrm{CH}}_{2}\right)_{15} \mathrm{CH}_{3}\right), 0.96-0.83(\mathrm{~m}, 3 \mathrm{H}$; $\left.\mathrm{OCH}_{2} \mathrm{CH}_{2}\left(\mathrm{CH}_{2}\right)_{15} \underline{\mathrm{CH}}_{3}\right)$.

5-[4-(R)-Methyl-2-phenoxypropionate]-10,15,20-[4octadecaneoxybenzene]porphyrin ((R)-4). (R)-Methyl 2-(4formylphenoxy)propanoate (2) (300.0 mg, $1.44 \mathrm{mmol}$ ) and 4octadecaneoxy-benzaldehyde (3) (1.60 g, $4.32 \mathrm{mmol})$ were dissolved in propionic acid $(15 \mathrm{~mL})$ and stirred under reflux for about $30 \mathrm{~min}$. Pyrrole $(0.40 \mathrm{~mL}, 5.76 \mathrm{mmol})$ was added dropwise and the mixture was stirred for $3 \mathrm{~h}$ under reflux. The 
solution was then cooled down at room temperature and was extracted with a saturate sodium bicarbonate solution and dried over $\mathrm{Na}_{2} \mathrm{SO}_{4}$ anhydrous. The solvent was removed under pressure. The crude compound $(R)-4$ was subjected to silica gel column chromatography $\left(7: 3\right.$ hexane $\left./ \mathrm{CH}_{2} \mathrm{Cl}_{2}\right)$ to obtain $347.5 \mathrm{mg}(15 \%)$ of the desired porphyrin. ${ }^{1} \mathrm{H}$ NMR (300 $\mathrm{MHz}, \mathrm{CDCl}_{3}$, r.t., ppm): $\delta 8.86(\mathrm{~m}, 8 \mathrm{H}$; pyrrole), 8.11 (d, $J=$ $\left.8.5 \mathrm{~Hz}, 6 \mathrm{H} ; \underline{\mathrm{PhOC}}_{18} \mathrm{H}_{37}\right), 7.29(\mathrm{~d}, J=8.5 \mathrm{~Hz}, 6 \mathrm{H}$;

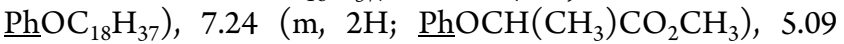
$\left(\mathrm{m}, 1 \mathrm{H} ; \mathrm{OCH}\left(\mathrm{CH}_{3}\right)\right), 4.25(\mathrm{t}, J=6.6 \mathrm{~Hz}, 6 \mathrm{H}$; $\left.\mathrm{OCH}_{2} \mathrm{CH}_{2}\left(\mathrm{CH}_{2}\right)_{15} \mathrm{CH}_{3}\right), 3.92\left(\mathrm{~s}, 3 \mathrm{H} ; \mathrm{CO}_{2} \underline{\mathrm{CH}}_{3}\right), 2.08-1.92$ (m, 6H; $\left.\mathrm{OCH}_{2} \underline{\mathrm{CH}}_{2}\left(\mathrm{CH}_{2}\right)_{15} \mathrm{CH}_{3}\right), 1.83(\mathrm{~d}, \mathrm{~J}=6.7 \mathrm{~Hz}, 3 \mathrm{H}$; $\left.\mathrm{OCH}\left(\underline{\mathrm{CH}}_{3}\right)\right), 1.27\left(\mathrm{~m}, 90 \mathrm{H} ; \mathrm{OCH}_{2} \mathrm{CH}_{2}\left(\underline{\mathrm{CH}}_{2}\right)_{15} \mathrm{CH}_{3}\right), 0.88(\mathrm{t}$, $\left.J=6.6 \mathrm{~Hz}, 9 \mathrm{H} ; \mathrm{OCH}_{2} \mathrm{CH}_{2}\left(\mathrm{CH}_{2}\right)_{15} \mathrm{CH}_{3}\right),-2.76(\mathrm{~s}, 2 \mathrm{H} ; \mathrm{NH})$; MF: $\mathrm{C}_{102} \mathrm{H}_{144} \mathrm{~N}_{4} \mathrm{O}_{6}$; MW: $1522.6 \mathrm{~g} / \mathrm{mol}$; found LDI-Tof $\left[\mathrm{M}^{+}\right]$: 1523.3; IR-ATR $\left(\mathrm{cm}^{-1}\right): 3319(\mathrm{w}, \mathrm{NH}), 2922\left(\mathrm{~s}, \mathrm{CH}_{2}\right), 2848$ (s, $\left.\mathrm{CH}_{2}\right), 1766$ (m, COOMe), 1746 (m, COOMe), 1606 (m, phenyl), 1506 (m, phenyl), 1238 (s), 963 (s), 799 (s); UV-vis $(\mathrm{MCH}) \lambda_{\max } / \mathrm{nm}\left(\varepsilon \mathrm{M}^{-1} \mathrm{~cm}^{-1}\right): 420$ (353 154), 517 (13 410), 553 (9478), 594 (4236), 652 (4936).

5-[4-(R)-Methyl-2-phenoxypropionate]-10,15,20-[4octadecaneoxybenzene]porphyrin Zinc(II) ((R)-5). The freebase porphyrin $(R)-4(70.5 \mathrm{mg}, 46 \mu \mathrm{mol})$ was dissolved in DCM $(6 \mathrm{~mL})$ and was stirred under reflux in an inert atmosphere. $\mathrm{Zn}(\mathrm{OAc})_{2}(29.54 \mathrm{mg}, 0.16 \mathrm{mmol})$ was dissolved in a 1:1 mixture of $\mathrm{CH}_{2} \mathrm{Cl}_{2} / \mathrm{MeOH}(3 \mathrm{~mL})$ and then was added dropwise with a syringe for over $5 \mathrm{~min}$. The reaction mixture was further refluxed for $3 \mathrm{~h}$. DCM was added and the organic layer was washed with saturated aqueous solution of $\mathrm{NaHCO}_{3}$, brine and was dried over anhydrous $\mathrm{Na}_{2} \mathrm{SO}_{4}$ and concentrated in vacuum. The crude metalloporphyrin $(R)-5$ was purified by a silica gel chromatography (15:85; hexane/ $\mathrm{CHCl}_{3}$ ), giving $54.5 \mathrm{mg}(74 \%)$ as a purple metallic powder. ${ }^{1} \mathrm{H}$ NMR (300 MHz, $\mathrm{CDCl}_{3}$, r.t., ppm): $\delta 9.05-8.94(\mathrm{~m}, 8 \mathrm{H}$; pyrrole), 8.19-8.06 (m, 8H; ArH), 7.31-7.27 (m, 8H; ArH), $5.06\left(\mathrm{q}, J=6.8 \mathrm{~Hz}, 1 \mathrm{H}\right.$; OCH$\left.\left(\mathrm{CH}_{3}\right)\right), 4.26(\mathrm{t}, J=6.5 \mathrm{~Hz}, 6 \mathrm{H}$; $\left.\mathrm{OCH}_{2} \mathrm{CH}_{2}\left(\mathrm{CH}_{2}\right)_{15} \mathrm{CH}_{3}\right), 3.92\left(\mathrm{~s}, 3 \mathrm{H} ; \mathrm{CO}_{2} \underline{\mathrm{CH}}_{3}\right), 2.07-1.93$ (m, 6H; $\left.\mathrm{OCH}_{2} \mathrm{CH}_{2}\left(\mathrm{CH}_{2}\right)_{15} \mathrm{CH}_{3}\right), 1.83(\mathrm{~d}, \mathrm{~J}=6.8 \mathrm{~Hz}, 3 \mathrm{H}$; $\left.\mathrm{OCH}\left(\mathrm{C} \mathrm{H}_{3}\right)\right), \quad 1.71-1.55 \quad(\mathrm{~m}, \quad 6 \mathrm{H}$; $\left.\mathrm{OCH}_{2} \mathrm{CH}_{2} \underline{\mathrm{CH}}_{2}\left(\mathrm{CH}_{2}\right)_{14} \mathrm{CH}_{3}\right), 1.31$ (s, $84 \mathrm{H}$; $\left.\mathrm{OCH}_{2} \mathrm{CH}_{2}\left(\underline{\mathrm{CH}}_{2}\right)_{15} \mathrm{CH}_{3}\right), 0.97-0.77(\mathrm{~m}, 9 \mathrm{H}$; $\left.\mathrm{OCH}_{2} \mathrm{CH}_{2}\left(\mathrm{CH}_{2}\right)_{15} \underline{\mathrm{CH}}_{3}\right) ; \mathrm{MF}: \mathrm{C}_{102} \mathrm{H}_{142} \mathrm{~N}_{4} \mathrm{O}_{6} \mathrm{Zn} ; \mathrm{MW}$ : $1585.6 \mathrm{~g} / \mathrm{mol}$; found LDI-Tof $\left[\mathrm{M}^{+}\right]$: 1586.2; UV-vis $\left(\mathrm{CHCl}_{3}\right) \lambda_{\text {max }} / \mathrm{nm}\left(\varepsilon \mathrm{M}^{-1} \mathrm{~cm}^{-1}\right): 420$ (360 782), 554 (14 284), 596 (3470).

5-[4-(R)-Methyl-2-phenoxypropanoic acid]-10,15,20-[4octadecaneoxybenzene]porphyrin Zinc(II) ((R)-6). Metalloporphyrin $(R)-5(70.0 \mathrm{mg}, 44 \mu \mathrm{mol})$ was dissolved in tetrahydrofuran (THF) $(2.5 \mathrm{~mL})$ and a solution $1.5 \mathrm{M}$ of $\mathrm{KOH}$ was added. The resulting mixture was stirred overnight at room temperature. The same solution was diluted in acidic water $(1 \mathrm{M} \mathrm{HCl})$ and extracted with $\mathrm{CHCl}_{3}$. The organic phase was dried over anhydrous $\mathrm{Na}_{2} \mathrm{SO}_{4}$ and filtered through cotton wool. After evaporation of the solvent the acid metalloporphyrin $(R)-6$ (58.7 mg, 85\%) was isolated. ${ }^{1} \mathrm{H}$ NMR (300 MHz, $\mathrm{CDCl}_{3}$, r.t., ppm): $\delta 8.96$ (s, $8 \mathrm{H}$; pyrrole), 8.09 (s, 8H; ArH), 7.21 (d, $J=9.6 \mathrm{~Hz}, 8 \mathrm{H} ; \mathrm{ArH}), 5.02(\mathrm{~s}, 1 \mathrm{H}$; $\left.\mathrm{OCH}\left(\mathrm{CH}_{3}\right)\right), 4.19\left(\mathrm{~m}, 6 \mathrm{H} ; \mathrm{OCH}_{2} \mathrm{CH}_{2}\left(\mathrm{CH}_{2}\right)_{15} \mathrm{CH}_{3}\right), 1.93(\mathrm{~s}$, $\left.3 \mathrm{H} ; \quad \mathrm{OCH}\left(\mathrm{CH}_{3}\right)\right), \quad 1.80-1.51 \quad(\mathrm{~m}, 6 \mathrm{H}$; $\left.\mathrm{OCH}_{2} \underline{\mathrm{CH}}_{2}\left(\mathrm{CH}_{2}\right)_{15} \mathrm{CH}_{3}\right), 1.51-1.12(\mathrm{~m}, 90 \mathrm{H}$; $\left.\mathrm{OCH}_{2} \mathrm{CH}_{2}\left(\mathrm{CH}_{2}\right)_{15} \mathrm{CH}_{3}\right), 1.02-0.74(\mathrm{~m}, 9 \mathrm{H}$; $\left.\mathrm{OCH}_{2} \mathrm{CH}_{2}\left(\mathrm{CH}_{2}\right)_{15} \mathrm{CH}_{3}\right)$.
3'-[5-((4-(R)-Methyl-2-phenoxyethoxyl)formylamino)10,15,20-[4-octadecaneoxybenzene]porphyrin]-2,2'-bipyridine-3-amine ((R)-8). The corresponding chiral acid metalloporphyrin $(R)-6(77.0 \mathrm{mg}, 49 \mu \mathrm{mol})$ was dissolved in dry THF $(5 \mathrm{~mL})$ and stirred under an argon atmosphere at $50{ }^{\circ} \mathrm{C}$. Oxalyl chloride $(12.6 \mu \mathrm{L}, 0.15 \mathrm{mmol})$ was added dropwise over the solution of acid metalloporphyrin and immediately a drop of pyridine (10\%) was added in the reaction. The mixture was stirred under an inert atmosphere for $3 \mathrm{~h}$. The solvent was then removed and the crude acid chloride thus obtained was used in the next step without further purification. 3,3'-diamino2,2' -bipyridine $7(9.2 \mathrm{mg}, 49 \mu \mathrm{mol})$ and triethylamine (TEA) $(7.5 \mu \mathrm{L}, 54 \mu \mathrm{mol})$ were dissolved in dry $\mathrm{CH}_{2} \mathrm{Cl}_{2}(1.5 \mathrm{~mL})$ under inert conditions and cooled down at $0{ }^{\circ} \mathrm{C}$. A cold solution of the acid chloride intermediate in dry $\mathrm{CH}_{2} \mathrm{Cl}_{2}(2.5$ $\mathrm{mL}$ ) was added dropwise over the 3,3'-diamino-2,2' -bipyridine solution. The resulting mixture was stirred from $0{ }^{\circ} \mathrm{C}(2 \mathrm{~h})$ to room temperature overnight. The organic layer was extracted with water $(\times 3)$ and brine $(\times 1)$, and dried over anhydrous $\mathrm{MgSO}_{4}$. The solution was filtered through cotton wool and the solvent was removed under pressure. The crude compound was subjected to silica gel column chromatography (eluent; 1:1 hexane/ $\mathrm{CH}_{2} \mathrm{Cl}_{2}$ to $7: 3 \mathrm{CH}_{2} \mathrm{Cl}_{2}$ /acetone) to obtain the desired porphyrin $(R)-8$ as a purple solid $(49.3 \mathrm{mg}, 60 \%) .{ }^{1} \mathrm{H}$ NMR (300 $\mathrm{MHz} \mathrm{CDCl}_{3}$, r.t., ppm): $\delta 14.35$ (s, 1H; CONH), 9.14 (d, $J=8.3 \mathrm{~Hz}, 1 \mathrm{H}$; bipy), 8.88 (s, $6 \mathrm{H}$; pyrrole), 8.77 (s, $2 \mathrm{H}$; pyrrole), 8.34 (s, $1 \mathrm{H}$; bipy), 8.11 (d, $J=7.2 \mathrm{~Hz}, 8 \mathrm{H}$; $\mathrm{ArH})$, 7.34 (d, $J=6.7 \mathrm{~Hz}, 2 \mathrm{H}$; ArH), 7.27 (d, J = 7.5 Hz, 6H; ArH), 7.26 (s, 1H; bipy), 7.13 (s, 1H; bipy), 7.05 (d, J = 7.8 Hz, 2H; bipy), 6.33 (s, $\left.2 \mathrm{H} ; \mathrm{NH}_{2}\right), 5.00\left(\mathrm{~s}, 1 \mathrm{H} ; \mathrm{OCH}\left(\mathrm{CH}_{3}\right)\right), 4.24(\mathrm{~s}$, $\left.6 \mathrm{H} ; \quad \mathrm{OCH}_{2} \mathrm{CH}_{2}\left(\mathrm{CH}_{2}\right)_{15} \mathrm{CH}_{3}\right), 1.97(\mathrm{~d}, \mathrm{~J}=6.2 \mathrm{~Hz}, 4 \mathrm{H}$; $\left.\mathrm{OCH}_{2} \underline{\mathrm{CH}}_{2}\left(\mathrm{CH}_{2}\right)_{15} \mathrm{CH}_{3}\right), 1.87$ (d, $\mathrm{J}=6.0 \mathrm{~Hz}, 3 \mathrm{H}$; OCH$\left.\left(\underline{\mathrm{CH}}_{3}\right)\right), 1.60(\mathrm{~d}, J=15.7 \mathrm{~Hz}, 8 \mathrm{H} ; 2 \mathrm{H}$; $\left.\mathrm{OCH}_{2} \underline{\mathrm{CH}}_{2}\left(\mathrm{CH}_{2}\right)_{15} \mathrm{CH}_{3}, 6 \mathrm{H} ; \quad \mathrm{OCH}_{2} \mathrm{CH}_{2} \underline{\mathrm{CH}}_{2}\left(\mathrm{CH}_{2}\right)_{14} \mathrm{CH}_{3}\right)$, 1.28 (s, 84H; $\left.\mathrm{OCH}_{2} \mathrm{CH}_{2} \mathrm{CH}_{2}\left(\underline{\mathrm{CH}}_{2}\right)_{14} \mathrm{CH}_{3}\right), 0.88$ (d, J = 6.3 $\left.\mathrm{Hz}, 9 \mathrm{H} ; \mathrm{OCH}_{2} \mathrm{CH}_{2}\left(\mathrm{CH}_{2}\right)_{15} \mathrm{CH}_{3}\right),-2.76$ (s, 2H; NH); MF: $\mathrm{C}_{111} \mathrm{H}_{150} \mathrm{~N}_{8} \mathrm{O}_{5}$; MW: $1676.4 \mathrm{~g} / \mathrm{mol}$; found MALDI-ToF $\left[\mathrm{M}^{+}\right]$: 1677.5 .

$3^{\prime}$-[5-((4-(R)-Methyl-2-phenoxyethoxyl)formylamino)10,15,20-[4-octadecaneoxybenzene]porphyrin Zinc(II)]-2,2'bipyridine-3-amine ((R)-9). The free-base porphyrin $(R)-8$ (49.3 $\mathrm{mg}, 0.03 \mathrm{mmol}$ ) was dissolved in $\mathrm{CH}_{2} \mathrm{Cl}_{2}(4.0 \mathrm{~mL})$ and the solution was stirred at reflux under an inert atmosphere. $\mathrm{Zn}(\mathrm{OAc})_{2}(20.31 \mathrm{mg}, 0.11 \mathrm{mmol})$ dissolved in a $1: 1$ mixture of $\mathrm{CH}_{2} \mathrm{Cl}_{2} / \mathrm{MeOH}(2.2 \mathrm{~mL})$ was added dropwise with a syringe over $5 \mathrm{~min}$. The reaction mixture was further refluxed for $3 \mathrm{~h} \mathrm{CH}_{2} \mathrm{Cl}_{2}$ was added and the organic layer was washed with saturated aqueous solution of sodium bicarbonate, brine and was dried over anhydrous $\mathrm{Na}_{2} \mathrm{SO}_{4}$ and concentrated in vacuum. The residue was purified by silica gel chromatography (85:15 hexane/DCM) giving the desired metalloporphyrin as a purple powder (32.5 mg, 63.5\%). ${ }^{1} \mathrm{H} \mathrm{NMR} \mathrm{(300} \mathrm{MHz} \mathrm{CDCl}_{3}$, r.t., ppm): $\delta 13.81$ (s, 1H; CONH), 8.96 (d, $J=16.8 \mathrm{~Hz}, 6 \mathrm{H}$; pyrrole), 8.82 (s, 2H; pyrrole), 8.13 (d, $J=9.9 \mathrm{~Hz}, 6 \mathrm{H}$; ArH), 8.01 (s, 2H; ArH), 8.01 (s, 1H, bipy), 7.78 (s, 2H; bipy), 7.30 (s, 8H; ArH), 6.99 (s, 3H; bipy), 6.78 (s, 1H; bipy), 5.87 (s, $2 \mathrm{H}$; bipy), 4.85 (s, $\left.1 \mathrm{H} ; \mathrm{OCH}\left(\mathrm{CH}_{3}\right)\right), 4.26(\mathrm{~s}, 6 \mathrm{H}$; $\left.\mathrm{OCH}_{2} \mathrm{CH}_{2}\left(\mathrm{CH}_{2}\right)_{15} \mathrm{CH}_{3}\right), 2.00\left(\mathrm{~s}, 3 \mathrm{H} ; \mathrm{OCH}\left(\underline{\mathrm{CH}}_{3}\right)\right), 1.30(\mathrm{~s}$, $\left.96 \mathrm{H} ; \quad \mathrm{OCH}_{2}\left(\underline{\mathrm{CH}}_{2}\right)_{16} \mathrm{CH}_{3}\right), 0.92$ ( s , $9 \mathrm{H}$; $\left.\mathrm{OCH}_{2} \mathrm{CH}_{2}\left(\mathrm{CH}_{2}\right)_{15} \underline{\mathrm{CH}}_{3}\right) ; \quad \mathrm{MF}$ : $\mathrm{C}_{111} \mathrm{H}_{148} \mathrm{~N}_{8} \mathrm{O}_{5} \mathrm{Zn}$; MW: $1739.8 \mathrm{~g} / \mathrm{mol}$; found MALDI-Tof $\left[\mathrm{M}^{+}\right]$: 1739.4; IR-ATR $\left(\mathrm{cm}^{-1}\right): 3416\left(\mathrm{bw}, \mathrm{NH}_{2}\right), 2922\left(\mathrm{~s}, \mathrm{CH}_{2}\right), 2851\left(\mathrm{~s}, \mathrm{CH}_{2}\right), 1658$ 
(m, CONH), 1604 (m, phenyl), 1506 (m, phenyl), 1237 (s), 992 (s), 800 (s).

$C_{3}$ Tris-metalloporphyrin $C_{3}-[Z n-(R, R, R)]-1$. A solution of (R)-9 (30 mg, $0.017 \mathrm{mmol})$ and TEA $(2.65 \mu \mathrm{L}, 0.019 \mathrm{mmol})$ in $2 \mathrm{~mL} \mathrm{CH} \mathrm{Cl}_{2}$ was cooled at $0{ }^{\circ} \mathrm{C}$, and then a solution of trimesic chloride $(1 \mu \mathrm{L}, 5.6 \mu \mathrm{mol})$ in $0.5 \mathrm{~mL} \mathrm{CH}_{2} \mathrm{Cl}_{2}$ was added dropwise. After $2 \mathrm{~h}$ of stirring at $0{ }^{\circ} \mathrm{C}$ and one night at room temperature, a purple precipitate was obtained. The solution was filtered and the precipitate washed with DCM, methanol, and diethyl ether. After drying, the product was obtained as a purple powder $(53.6 \mathrm{mg}, 59 \%) .{ }^{1} \mathrm{H}$ NMR (300 $\mathrm{MHz}, \mathrm{CDCl}_{3}$, r.t., ppm): $\delta 13.85$ (s, CONH), 8.91 (s, pyrrole), 8.78 (s, pyrrole), 8.17-7.92 (m, ArH), 7.90-7.85 (m, bipy), 7.24 (d, $J=11.4 \mathrm{~Hz}, \mathrm{ArH}$ ), 6.98 (s, bipy), 6.85 (d, $J=8.7 \mathrm{~Hz}$, bipy), 5.00 (s, $\left.\mathrm{OCH}\left(\mathrm{CH}_{3}\right)\right), 4.20\left(\mathrm{~s}, \mathrm{OCH}_{2} \mathrm{CH}_{2}\left(\mathrm{CH}_{2}\right)_{15} \mathrm{CH}_{3}\right)$, $1.94\left(\mathrm{~s}, \mathrm{OCH}\left(\underline{\mathrm{CH}}_{3}\right)\right), 1.24\left(\mathrm{~s}, \mathrm{OCH}_{2}\left(\underline{\mathrm{CH}}_{2}\right)_{16} \mathrm{CH}_{3}\right), 0.92-0.79$ (m, $\left.\mathrm{OCH}_{2} \mathrm{CH}_{2}\left(\mathrm{CH}_{2}\right)_{15} \underline{\mathrm{CH}}_{3}\right)$; MF: $\mathrm{C}_{342} \mathrm{H}_{444} \mathrm{~N}_{24} \mathrm{O}_{18} \mathrm{Zn}_{3} ; \mathrm{MW}$ : $5375.47 \mathrm{~g} / \mathrm{mol}$; found MALDI-ToF $\left[\mathrm{M}^{+}\right]$: 5372.3 .

Bis-[3, 3'-[5-((4-(R)-methyl-2-phenoxyethoxyl)formylamino)-10,15,20-[4-octadecaneoxybenzene]porphyrin]]-2,2'-bipyridine $((R, R)-10)$. The corresponding chiral acid metalloporphyrin $(R)-6(150.0 \mathrm{mg}, 0.095 \mathrm{mmol})$ was dissolved in dry THF $(10 \mathrm{~mL})$ and stirred under an argon atmosphere at $50{ }^{\circ} \mathrm{C}$. Oxalyl chloride $(24.6 \mu \mathrm{L}, 0.29 \mathrm{mmol})$ was added dropwise over the solution of the acid metalloporphyrin and immediately a drop of pyridine (10\%) was added in the reaction. The mixture was stirred under an inert atmosphere for $3 \mathrm{~h}$. The solvent was removed under reduced pressure for $1 \mathrm{~h}$, and then the crude acid chloride was used in the next step without further purification. 3,3'-diamino-2,2'bipyridine 7 (9.2 $\mathrm{mg}, 0.048 \mathrm{mmol})$ and TEA $(13.9 \mu \mathrm{L}, 0.1$ mmol) were dissolved in dry $\mathrm{CH}_{2} \mathrm{Cl}_{2}(1.5 \mathrm{~mL})$ under inert conditions and cooled down at $0{ }^{\circ} \mathrm{C}$. A cold solution of the acid chloride intermediate in dry $\mathrm{CH}_{2} \mathrm{Cl}_{2}(5 \mathrm{~mL})$ was added dropwise over the $3,3^{\prime}$-diamino-2,2'-bipyridine solution. The resulting mixture was stirred from $0{ }^{\circ} \mathrm{C}(2 \mathrm{~h})$ to room temperature overnight. The organic layer was extracted with water $(3 \times 10 \mathrm{~mL})$ and brine $(1 \times 10 \mathrm{~mL})$ and dried over anhydrous $\mathrm{MgSO}_{4}$. The solution was filtered through cotton wool and the solvent was removed under pressure. The crude compound was subjected to a silica gel column chromatography (eluent; $\mathrm{CH}_{2} \mathrm{Cl}_{2}$ to $7: 3 \mathrm{CH}_{2} \mathrm{Cl}_{2} / 10 \% \mathrm{MeOH}$ ) to obtain the bis(porphyrin) $(R, R)-10(65.7 \mathrm{mg}, 43 \%) .{ }^{1} \mathrm{H}$ NMR (300 $\mathrm{MHz}, \mathrm{CDCl}_{3}$, r.t., ppm): $\delta 14.17$ (s, 2H; CONH), $8.93(\mathrm{~m}$, $4 \mathrm{H}$; pyrrole), 8.87 (m, $8 \mathrm{H}$; pyrrole), $8.76(\mathrm{t}, \mathrm{J}=5.2 \mathrm{~Hz}, 4 \mathrm{H}$; pyrrole), 8.70 (d, $J=8.5 \mathrm{~Hz}, 1 \mathrm{H}$; bipy), 8.07 (m, 16H; ArH), 7.75 (m, 2H; bipy), 7.27 (m, 13H; 12H; ArH, 1H; bipy), 7.18 (m, 2H; bipy), 6.99 (m, 4H; $\mathrm{ArH}), 4.76$ (s, 2H; OCH$\left(\mathrm{CH}_{3}\right)$ ), $4.21\left(\mathrm{~m}, 12 \mathrm{H} ; \mathrm{OCH}_{2} \mathrm{CH}_{2}\left(\mathrm{CH}_{2}\right)_{15} \mathrm{CH}_{3}\right), 1.95(\mathrm{~m}, 12 \mathrm{H}$; $\left.\mathrm{OCH}_{2} \mathrm{CH}_{2}\left(\mathrm{CH}_{2}\right)_{15} \mathrm{CH}_{3}\right), 1.62(\mathrm{~d}, \mathrm{~J}=6.0 \mathrm{~Hz}, 6 \mathrm{H}$; OCH$\left.\left(\underline{\mathrm{CH}}_{3}\right)\right), 1.30$ (m, 180H; $\left.\mathrm{OCH}_{2} \mathrm{CH}_{2}\left(\underline{\mathrm{CH}}_{2}\right)_{15} \mathrm{CH}_{3}\right), 0.90(\mathrm{t}, \mathrm{J}=$ $\left.6.4 \mathrm{~Hz}, 18 \mathrm{H} ; \mathrm{OCH}_{2} \mathrm{CH}_{2}\left(\mathrm{CH}_{2}\right)_{15} \mathrm{CH}_{3}\right),-2.77$ (s, $\left.4 \mathrm{H} ; \mathrm{NH}\right)$; MF: $\mathrm{C}_{212} \mathrm{H}_{290} \mathrm{~N}_{12} \mathrm{O}_{10}$; MW: $3166.7 \mathrm{~g} / \mathrm{mol}$; found MALDI-ToF $\left[\mathrm{M}^{+}\right]$: 3167.6.

CD and UV-Vis Measurements. Jasco J-275 and Jasco J815 spectropolarimeters were used for $C D$ spectra measurements. A Peltier-temperature programmer was used to perform variable temperature measurements. The solutions were prepared by diluting a solid sample either of $C_{3^{-}}-[\mathrm{Zn}$ $(R, R, R)]-1$ or bis-porphyrin $(R, R)-10$ in the corresponding amount of the solvent and the solution was heated until all the compounds had dissolved to obtain $5 \mu \mathrm{M}$ as a final concentration. The samples were transferred to a standard quartz cuvette of $1 \mathrm{~cm}$ length to be analyzed. When the measurement temperature was reached and stabilized, spectra were recorded. UV-visible absorption measurements were performed using a UV-vis-NIR Varian, model Cary 5 instrument using a $1 \mathrm{~cm}$ length standard quartz cuvette. All the samples were prepared by diluting a solid sample of $C_{3^{-}}$$[\mathrm{Zn}-(R, R, R)]-1$ in the corresponding amounts of the solvent. The solution was heated until all the compounds dissolved to obtain $5 \mu \mathrm{M}$ as a final concentration.

Computational Details. MM with the MM3 force field were used to identify the different conformers for both bis(porphyrin) $(R, R)-10$ and for $C_{3}-[\mathrm{Zn}-(R, R, R)]-1$. DFT calculations were performed with the Gaussian program, and optimizations were done at the B3LYP/6-31G(D) level of theory with an empirical correction to take into account dispersion for both bis(porphyrin) $(R, R)-10$ and for $C_{3^{-}}$-[Zn$(R, R, R)]-1$. Absorption and CD spectra were calculated at the CAM-B3LYP/6-31+G(d) level of theory for the bis(porphyrin) $(R, R)-10$. The first 10 excited states were calculated and were broadened with a Gaussian function with a full width at half maximum of $0.1 \mathrm{eV}$.

For $C_{3}-[\mathrm{Zn}-(R, R, R)]-\mathbf{1}, \mathrm{MD}$ simulations were performed using the Gromacs program package ${ }^{72-74}$ in combination with the GROMOS 54B7 force field. ${ }^{75}$ In all simulations, we used periodic boundary conditions. MD simulations in an NPT ensemble were carried out maintaining the temperature at 300 $\mathrm{K}$ with the v-Rescale thermostat and coupling constant of 0.2 ps. A Berendsen barostat with a coupling constant of 1 ps was employed to maintain the pressure at $1 \mathrm{~atm}$. MD simulations in the NVT ensemble were carried out maintaining the temperature at $300 \mathrm{~K}$ with a v-Rescale thermostat and coupling constant of 0.2 ps. The electrostatic and van der Waals interactions were both calculated with a cut-off distance of 1.5 $\mathrm{nm}$.

The boxes of solvents were obtained after simulation in the NPT ensemble for $50 \mathrm{~ns}$ with a converged density of 776 and $1528 \mathrm{~kg} / \mathrm{m}^{3}$ for dodecane and chloroform, respectively. Boxes of $12 \times 12 \times 12 \mathrm{~nm}^{3}$ were then created by solvating a single molecule in two conformations (open and folded) or dimer in the two solvents. MD simulations were carried out for $50 \mathrm{~ns}$ in the NVT ensemble.

\section{ASSOCIATED CONTENT}

\section{S Supporting Information}

The Supporting Information is available free of charge on the ACS Publications website at DOI: 10.1021/acsomega.9b01050.

MALDI-TOF and CD spectra of the porphyrin compounds, optimized geometries for the achiral bis(porphyrins) and the $M$ conformer of the bis(porphyrin) $(R, R)-10$, Coulombic and Lennard-Jones interaction between the two molecules of $C_{3}$ - $[\mathrm{Zn}$ $(R, R, R)]-1$, and tapping mode AFM images of $C_{3}-[\mathrm{Zn}-$ $(R, R, R)]-1$ on freshly cleaved mica (PDF)

\section{AUTHOR INFORMATION}

\section{Corresponding Authors}

*E-mail: David.Amabilino@nottingham.ac.uk (D.B.A.).

*E-mail: narcis.avarvari@univ-angers.fr (N.A.). Fax: (+33)02 41735405.

ORCID $\odot$

Mathieu Linares: 0000-0002-9720-5429 
David B. Amabilino: 0000-0003-1674-8462

Narcis Avarvari: 0000-0001-9970-4494

\section{Notes}

The authors declare no competing financial interest.

\section{ACKNOWLEDGMENTS}

Financial support from the Région Pays de la Loire through the RFI LUMOMAT project CHISUMAT (grant to C.O.-G.), the University of Angers and the CNRS is gratefully acknowledged. D.B.A. thanks the University of Nottingham Propulsion Futures Beacon and EPSRC (EP/M005178/1) for funding. M.L. thanks SERC (Swedish e-Science Research Center) for funding and SNIC for providing computer resources. I. Freuze (Univ. Angers) is thanked for performing the MS analysis. Biosit facility (Université de Rennes 1) is acknowledged for the access to the CD instrument.

\section{REFERENCES}

(1) Busseron, E.; Ruff, Y.; Moulin, E.; Giuseppone, N. Supramolecular Self-Assemblies as Functional Nanomaterials. Nanoscale 2013, 5, 7098-7140.

(2) Babu, S. S.; Praveen, V. K.; Ajayaghosh, A. Functional $\pi$-Gelators and Their Applications. Chem. Rev. 2014, 114, 1973-2129.

(3) Rest, C.; Kandanelli, R.; Fernandez, G. Strategies to Create Hierarchical Self-Assembled Structures via Cooperative Non-Covalent Interactions. Chem. Soc. Rev. 2015, 44, 2543-2572.

(4) Fernández, S.; Pisula, W.; Geerts, Y. H. Discotic Liquid Crystals: A New Generation of Organic Semiconductors. Chem. Soc. Rev. 2007, 36, 1902-1929.

(5) Beltrán, E.; Serrano, J. L.; Sierra, T.; Giménez, R. Functional Star-Shaped Tris(triazolyl)triazines: Columnar Liquid Crystal, Fluorescent, Solvatofluorochromic and Electrochemical Properties. J. Mater. Chem. 2012, 22, 7797-7805.

(6) García-Iglesias, M.; de Waal, B. F. M.; Gorbunov, A. V.; Palmans, A. R. A.; Kemerink, M.; Meijer, E. W. A Versatile Method for the Preparation of Ferroelectric Supramolecular Materials via Radical End-Functionalization of Vinylidene Fluoride Oligomers. J. Am. Chem. Soc. 2016, 138, 6217-6223.

(7) Shu, W.; Valiyaveettil, S. Intramolecular hydrogen bond assisted planarization and self-assembly of simple disc-shaped molecules in mesophasesElectronic supplementary information (ESI) available: synthetic procedures for compounds 1-3 and crystallographic details for 3. See http://www.rsc.org/suppdata/cc/b2/b201742c/. Chem. Commun. 2002, 1350-1351.

(8) Boden, N.; Bushby, R. J.; Hardy, C.; Sixl, F. Phase Behaviour and Structure of A Non-Ionic Discoidal Amphiphile in Water. Chem. Phys. Lett. 1986, 123, 359-364.

(9) Kanibolotsky, A. L.; Perepichka, I. F.; Skabara, P. J. Star-Shaped $\pi$-Conjugated Oligomers and Their Applications in Organic Electronics and Photonics. Chem. Soc. Rev. 2010, 39, 2695-2728.

(10) Cantekin, S.; de Greef, T. F. A.; Palmans, A. R. A. Benzene1,3,5-Tricarboxamide: A Versatile Ordering Moiety for Supramolecular Chemistry. Chem. Soc. Rev. 2012, 41, 6125-6137.

(11) Haedler, A. T.; Meskers, S. C. J.; Zha, R. H.; Kivala, M.; Schmidt, H.-W.; Meijer, E. W. Pathway Complexity in the Enantioselective Self-Assembly of Functional Carbonyl-Bridged Triarylamine Trisamides. J. Am. Chem. Soc. 2016, 138, 10539-10545.

(12) García, F.; Sánchez, L. Structural Rules for the Chiral Supramolecular Organization of OPE-based Discotics: Induction of Helicity and Amplification of Chirality. J. Am. Chem. Soc. 2012, 134, 734-742.

(13) Kulkarni, C.; Meijer, E. W.; Palmans, A. R. A. Cooperativity Scale: A Structure-Mechanism Correlation in the Self-Assembly of Benzene-1,3,5-tricarboxamides. Acc. Chem. Res. 2017, 50, 1928-1936.

(14) Baker, M. B.; Albertazzi, L.; Voets, I. K.; Leenders, C. M. A.; Palmans, A. R. A.; Pavan, G. M.; Meijer, E. W. Consequences of
Chirality on the Dynamics of A Water-Soluble Supramolecular Polymer. Nat. Commun. 2015, 6, 6234.

(15) Jana, P.; Schmuck, C. Self-Assembly of a Tripodal Triszwitterion Forms a pH-Switchable Hydrogel that Can Reversibly Encapsulate Hydrophobic Guests in Water. Chem.-Eur. J. 2017, 23, $320-326$.

(16) Narayan, B.; Kulkarni, C.; George, S. J. Synthesis and SelfAssembly of $\mathrm{A} \mathrm{C}_{3}$-Symmetric Benzene-1,3,5-tricarboxamide (BTA) Anchored Naphthalene Diimide Disc. J. Mater. Chem. C 2013, 1, 626-629.

(17) Dai, Y.; Zhao, X.; Su, X.; Li, G.; Zhang, A. Supramolecular Assembly of $\mathrm{C}_{3}$ Peptidic Molecules into Helical Polymers. Macromol. Rapid Commun. 2014, 35, 1326-1331.

(18) Kind, J.; Kaltschnee, L.; Leyendecker, M.; Thiele, C. M. Distinction of trans-cis Photoisomers with Comparable Optical Properties in Multiple-State Photochromic Systems - Examining a Molecule with Three Azobenzenes via in situ Irradiation NMR Spectroscopy. Chem. Commun. 2016, 52, 12506-12509.

(19) Wang, D.; Huang, Y.; Li, J.; Xu, L.; Chen, M.; Tao, J.; Li, L. Lyotropic Supramolecular Helical Columnar Phases Formed by $C_{3^{-}}$ Symmetric and Unsymmetric Rigid Molecules. Chem.-Eur. J. 2013, 19, 685-690.

(20) Cantekin, S.; Balkenende, D. W. R.; Smulders, M. M. J.; Palmans, A. R. A.; Meijer, E. W. The Effect of Isotopic Substitution on the Chirality of a Self-Assembled Helix. Nat. Chem. 2011, 3, 4246.

(21) Palmans, A. R. A.; Meijer, E. W. Amplification of Chirality in Dynamic Supramolecular Aggregates. Angew. Chem., Int. Ed. 2007, 46, $8948-8968$

(22) Brunsveld, L.; Zhang, H.; Glasbeek, M.; Vekemans, J. A. J. M.; Meijer, E. W. Hierarchical Growth of Chiral Self-Assembled Structures in Protic Media. J. Am. Chem. Soc. 2000, 122, 6175-6182. (23) van Gorp, J. J.; Vekemans, J. A. J. M.; Meijer, E. W. $C_{3-}$ Symmetrical Supramolecular Architectures: Fibers and Organic Gels from Discotic Trisamides and Trisureas. J. Am. Chem. Soc. 2002, 124, 14759-14769.

(24) Palmans, A. R. A.; Vekemans, J. A. J. M.; Meijer, E. W. Intramolecular Hydrogen Bonding in Acylated 2,2'-Bipyridine-3,3'diamines. Recl. Trav. Chim. Pays-Bas 1995, 114, 277-284.

(25) Palmans, A. R. A.; Vekemans, J. A. J. M.; Havinga, E. E.; Meijer, E. W. Sergeants-and-Soldiers Principle in Chiral Columnar Stacks of Disc-Shaped Molecules with $C_{3}$ Symmetry. Angew. Chem., Int. Ed. Engl. 1997, 36, 2648-2651.

(26) Danila, I.; Riobé, F.; Puigmartí-Luis, J.; Pérez del Pino, Á.; Wallis, J. D.; Amabilino, D. B.; Avarvari, N. Supramolecular Electroactive Organogel and Conducting Nanofibers with $\mathrm{C}_{3}$ Symmetrical Architectures. J. Mater. Chem. 2009, 19, 4495-4504.

(27) Lai, T.-L.; Pop, F.; Melan, C.; Canevet, D.; Sallé, M.; Avarvari, N. Triggering Gel Formation and Luminescence through DonorAcceptor Interactions in a $C_{3}$-Symmetric Tris(pyrene) System. Chem.-Eur. J. 2016, 22, 5839-5843.

(28) van Houtem, M. H. C. J.; Martín-Rapún, R.; Vekemans, J. A. J. M.; Meijer, E. W. Desymmetrization of 3,3'-Bis(acylamino)-2,2'bipyridine-Based Discotics: The High Fidelity of Their Self-Assembly Behavior in the Liquid-Crystalline State and in Solution. Chem.-Eur. J. 2010, 16, 2258-2271

(29) van Gestel, J.; Palmans, A. R. A.; Titulaer, B.; Vekemans, J. A. J. M.; Meijer, E. W. "Majority-Rules" Operative in Chiral Columnar Stacks ofC3-Symmetrical Molecules. J. Am. Chem. Soc. 2005, 127, 5490-5494.

(30) Gillissen, M. A. J.; Koenigs, M. M. E.; Spiering, J. J. H.; Vekemans, J. A. J. M.; Palmans, A. R. A.; Voets, I. K.; Meijer, E. W. Triple Helix Formation in Amphiphilic Discotics: Demystifying Solvent Effects in Supramolecular Self-Assembly. J. Am. Chem. Soc. 2014, 136, 336-343.

(31) van der Zwaag, D.; Pieters, P. A.; Korevaar, P. A.; Markvoort, A. J.; Spiering, A. J. H.; de Greef, T. F. A.; Meijer, E. W. Kinetic Analysis as a Tool to Distinguish Pathway Complexity in Molecular Assembly: 
An Unexpected Outcome of Structures in Competition. J. Am. Chem. Soc. 2015, 137, 12677-12688.

(32) Danila, I.; Riobé, F.; Piron, F.; Puigmartí-Luis, J.; Wallis, J. D.; Linares, M.; Ågren, H.; Beljonne, D.; Amabilino, D. B.; Avarvari, N. Hierarchical Chiral Expression from the Nano- to Mesoscale in Synthetic Supramolecular Helical Fibers of a NonamphiphilicC3Symmetrical $\pi$-Functional Molecule. J. Am. Chem. Soc. 2011, 133, 8344-8353.

(33) Danila, I.; Pop, F.; Escudero, C.; Feldborg, L. N.; PuigmartíLuis, J.; Riobé, F.; Avarvari, N.; Amabilino, D. B. Twists and turns in the hierarchical self-assembly pathways of a non-amphiphilic chiral supramolecular material. Chem. Commun. 2012, 48, 4552-4554.

(34) Riba-Moliner, M.; Avarvari, N.; Amabilino, D. B.; GonzálezCampo, A.; Gómez, A. Distinguishing between Mechanical and Electrostatic Interaction in Single Pass Multi Frequency Electrostatic Force Microscopy Measurements on a Molecular Material. Langmuir 2016, 32, 13593-13599.

(35) Das, A.; Ghosh, S. To Assemble or Fold? Chem. Commun. 2014, 50, 11657-11660.

(36) Lai, T.-L.; Canevet, D.; Avarvari, N.; Sallé, M. Internal Probing of the Supramolecular Organisation of Pyrene-Based Organogelators. Chem.-Asian J. 2016, 11, 81-85

(37) Tyndall, J. D. A.; Nall, T.; Fairlie, D. P. Proteases Universally Recognize Beta Strands In Their Active Sites. Chem. Rev. 2005, 105, 973-1000.

(38) Tsunoda, S. P.; Rodgers, A. J. W.; Aggeler, R.; Wilce, M. C. J.; Yoshida, M.; Capaldi, R. A. Large Conformational Changes of the $\varepsilon$ Subunit in the Bacterial $\mathrm{F}_{1} \mathrm{~F}_{0}$ ATP Synthase Provide a Ratchet Action to Regulate this Rotary Motor Enzyme. Proc. Natl. Acad. Sci. U.S.A. 2001, 98, 6560-6564.

(39) Rodriguez, A. D.; Dunn, S. D.; Konermann, L. ATP-Induced Dimerization of the $\mathrm{F}_{0} \mathrm{~F}_{1} \varepsilon$ Subunit from Bacillus PS3: A Hydrogen Exchange-Mass Spectrometry Study. Biochemistry 2014, 53, 40724080.

(40) Kuppuraj, G.; Sargsyan, K.; Hua, Y.-H.; Merrill, A. R.; Lim, C. Linking Distinct Conformations of Nicotinamide Adenine Dinucleotide with Protein Fold/Function. J. Phys. Chem. B 2011, 115, 79327939.

(41) Heiner, Z.; Roland, T.; Leonard, J.; Haacke, S.; Groma, G. I. Kinetics of Light-Induced Intramolecular Energy Transfer in Different Conformational States of NADH. J. Phys. Chem. B 2017, 121, 80378045 .

(42) Babu, S. S.; Bonifazi, D. Self-Organization of Polar Porphyrinoids. ChemPlusChem 2014, 79, 895-906.

(43) Renger, T.; Schlodder, E. Primary Photophysical Processes in Photosystem II: Bridging the Gap between Crystal Structure and Optical Spectra. ChemPhysChem 2010, 11, 1141-1153.

(44) Ohtani, Y.; Shimada, T.; Takagi, S. Artificial Light-Harvesting System with Energy Migration Functionality in a Cationic Dye/ Inorganic Nanosheet Complex. J. Phys. Chem. C 2015, 119, 1889618902.

(45) Kahlfuss, C.; Wytko, J. A.; Weiss, J. From Models of Hemoproteins to Self-Assembled Molecular Wires. ChemPlusChem 2017, 82, 584-594.

(46) Li, L.-L.; Diau, E. W.-G. Porphyrin-Sensitized Solar Cells. Chem. Soc. Rev. 2013, 42, 291-304.

(47) Rauch, V.; Conradt, J.; Takahashi, M.; Kanesato, M.; Wytko, J. A.; Kikkawa, Y.; Kalt, H.; Weiss, J. Self-Organized Porphyrin Arrays on Surfaces: the Case of Hydrophilic Side Chains and Polar Surfaces. J. Porphyrins Phthalocyanines 2014, 18, 67-75.

(48) Ding, Y.; Tang, Y.; Zhu, W.; Xie, Y. Fluorescent and Colorimetric Ion Probes Based on Conjugated Oligopyrroles. Chem. Soc. Rev. 2015, 44, 1101-1112.

(49) Andernach, R. E.; Rossbauer, S.; Ashraf, R. S.; Faber, H.; Anthopoulos, T. D.; McCulloch, I.; Heeney, M.; Bronstein, H. A. Conjugated Polymer-Porphyrin Complexes for Organic Electronics. ChemPhysChem 2015, 16, 1223-1230.

(50) Longevial, J.-F.; Clément, S.; Wytko, J. A.; Ruppert, R.; Weiss, J.; Richeter, S. Peripherally Metalated Porphyrins with Applications in
Catalysis, Molecular Electronics and Biomedicine. Chem.-Eur. J. 2018, 24, 15442-15460.

(51) Liu, H.; Xu, J.; Li, Y.; Li, Y. Aggregate Nanostructures of Organic Molecular Materials. Acc. Chem. Res. 2010, 43, 1496-1508.

(52) Senge, M. O.; Fazekas, M.; Notaras, E. G. A.; Blau, W. J.; Zawadzka, M.; Locos, O. B.; Ni Mhuircheartaigh, E. M. Nonlinear Optical Properties of Porphyrins. Adv. Mater. 2007, 19, 2737-2774.

(53) van Hameren, R.; Schon, P.; van Buul, A. M.; Hoogboom, J.; Lazarenko, S. V.; Gerritsen, J. W.; Engelkamp, H.; Christianen, P. C. M.; Heus, H. A.; Maan, J. C.; Rasing, T.; Speller, S.; Rowan, A. E.; Elemans, J. A. A. W.; Nolte, R. J. M. Macroscopic Hierarchical Surface Patterning of Porphyrin Trimers via Self-Assembly and Dewetting. Science 2006, 314, 1433-1436.

(54) Vela, S.; Berrocal, J. A.; Atienza, C.; Meijer, E. W.; Martín, N. Mesoscopic Helical Architectures via Self-Assembly of PorphyrinBased Discotic Systems. Chem. Commun. 2017, 53, 4084-4087.

(55) Oliveras-González, C.; Di Meo, F.; González-Campo, A.; Beljonne, D.; Norman, P.; Simón-Sorbed, M.; Linares, M.; Amabilino, D. B. Bottom-Up Hierarchical Self-Assembly of Chiral Porphyrins through Coordination and Hydrogen Bonds. J. Am. Chem. Soc. 2015, 137, 15795-15808.

(56) Pescitelli, G.; Gabriel, S.; Wang, Y.; Fleischhauer, J.; Woody, R. W.; Berova, N. Theoretical Analysis of the Porphyrin-Porphyrin Exciton Interaction in Circular Dichroism Spectra of Dimeric Tetraarylporphyrins. J. Am. Chem. Soc. 2003, 125, 7613-7628.

(57) Minguet, M.; Amabilino, D. B.; Vidal-Gancedo, J.; Wurst, K.; Veciana, J. Racemic and enantiomerically pure phenyl $\alpha$-nitronyl nitroxide radicals: influence of chirality on solution and solid state propertiesElectronic supplementary information (ESI) available: figures showing alternative views of the crystal structures and the shortest distances between SOMOs in the crystals. See http:// www.rsc.org/suppdata/jm/b1/b106239p/. J. Mater. Chem. 2002, 12, $570-578$.

(58) Eleftheriadis, N.; Thee, S.; te Biesebeek, J.; van der Wouden, P.; Baas, B.-J.; Dekker, F. J. Identification of 6-Benzyloxysalicylates as a Novel Class of Inhibitors of 15-Lipoxygenase-1. Eur. J. Med. Chem. 2015, 94, 265-275.

(59) Rice, C. R.; Onions, S.; Vidal, N.; Wallis, J. D.; Senna, M.-C.; Pilkington, M.; Stoeckli-Evans, H. The Coordination Chemistry of 3,3-Diamino-2,2-bipyridine and Its Dication: Exploring the Role of the Amino Groups by X-ray Crystallography. Eur. J. Inorg. Chem. 2002, 1985-1997.

(60) Hambright, P.; Fleisher, E. B. Acid-base Equilibriums, Kinetics of Copper Ion Incorporation, and Acid-Catalyzed Zinc Ion Displacement from the Water-Soluble Porphyrin $\alpha, \beta, \gamma, \delta$-Tetra(4-Nmethylpyridyl)porphine. Inorg. Chem. 1970, 9, 1757-1761.

(61) Berova, N.; Bari, L. D.; Pescitelli, G. Application of Electronic Circular Dichroism in Configurational and Conformational Analysis of Organic Compounds. Chem. Soc. Rev. 2007, 36, 914-931.

(62) Hoeben, F. J. M.; Jonkheijm, P.; Meijer, E. W.; Schenning, A. P. H. J. About Supramolecular Assemblies of $\pi$-Conjugated Systems. Chem. Rev. 2005, 105, 1491-1546.

(63) http://murov.info/orgsolvents.htm, 2019.

(64) Pescitelli, G.; Di Bari, L.; Berova, N. Application of Electronic Circular Dichroism in the Study of Supramolecular Systems. Chem. Soc. Rev. 2014, 43, 5211-5233.

(65) Matile, S.; Berova, N.; Nakanishi, K.; Fleischhauer, J.; Woody, R. W. Structural Studies by Exciton Coupled Circular Dichroism over a Large Distance: Porphyrin Derivatives of Steroids, Dimeric Steroids, and Brevetoxin B. J. Am. Chem. Soc. 1996, 118, 5198-5206.

(66) Su, Y.; Gao, X.; Liu, J.; Xing, R.; Han, Y. Uniaxial Alignment of Triisopropylsilylethynyl Pentacene via Zone-Casting Technique. Phys. Chem. Chem. Phys. 2013, 15, 14396-14404.

(67) Jonkheijm, P.; Hoeben, F. J. M.; Kleppinger, R.; Van Herrikhuyzen, J.; Schenning, A. P. H. J.; Meijer, E. W. Transfer of $\pi$-Conjugated Columnar Stacks from Solution to Surfaces. J. Am. Chem. Soc. 2003, 125, 15941-15949. 
(68) De Feyter, S.; De Schryver, F. C. Two-Dimensional Supramolecular Self-Assembly Probed by Scanning Tunneling Microscopy. Chem. Soc. Rev. 2003, 32, 139-150.

(69) Nakagawa, T.; Ogawa, K.; Kurumizawa, T. Atomic Force Microscope Images of Monolayers from Alkyltrichlorosilane on Mica Surfaces and Studies on an Anchoring Mechanism of Alkyltrichlorosilane Molecules to the Surface. Langmuir 1994, 10, 525-529.

(70) Tiberg, F.; Brinck, J.; Grant, L. Adsorption and Surface-Induced Self-Assembly of Surfactants at the Solid-Aqueous Interface. Curr. Opin. Colloid Interface Sci. 1999, 4, 411-419.

(71) Amabilino, D. B.; Smith, D. K.; Steed, J. W. Supramolecular materials. Chem. Soc. Rev. 2017, 46, 2404-2420.

(72) Berendsen, H. J. C.; van der Spoel, D.; van Drunen, R. GROMACS: A message-passing parallel molecular dynamics implementation. Comput. Phys. Commun. 1995, 91, 43-56.

(73) Lindahl, E.; Hess, B.; van der Spoel, D. GROMACS 3.0: A Package for Molecular Simulation and Trajectory Analysis. J. Mol. Model. 2001, 7, 306-317.

(74) van der Spoel, D.; Lindahl, E.; Hess, B.; Groenhof, G.; Mark, A. E.; Berendsen, H. J. C. GROMACS: Fast, Flexible, and Free. J. Comput. Chem. 2005, 26, 1701-1718.

(75) Schmid, N.; Eichenberger, A. P.; Choutko, A.; Riniker, S.; Winger, M.; Mark, A. E.; van Gunsteren, W. F. Definition and Testing of the GROMOS Force-Field Versions 54A7 and 54B7. Eur. Biophys. J. 2011, 40, 843-856. 